\title{
Fundamentals of Relationship Marketing
}

\section{Learning Objectives}

After studying this chapter you should be able to:

- understand the evolution of relationship marketing (RM)

- define RM

- describe what part loyalty schemes play in relationship development

- name the different cost drivers associated with customers acquisition and customer retention

- discuss the benefits of relationship longevity

- explain the drivers of relationship management

- describe RM's context within marketing management

- understand why marketing planning is so important

- discuss the process of marketing planning

- describe the concept of the business mission

- describe rewards and problems associated with marketing planning 


\subsection{The Evolution of Relationship Marketing}

Although relationship marketing (RM) is rising as a new phenomenon, relationship oriented marketing practices date back to the pre-industrial era. In this section, we trace the history of marketing practices and illustrate how the advent of mass production, the emergence of middlemen, and the separation of the producer from the customer in the industrial era led to a transactional focus of marketing. Now, due to technological advances, direct marketing is staging a comeback, leading to a relationship orientation.

Even though marketing practices can be traced back as far as 7000 B.C. (Carratu, 1987), marketing thought as a specific discipline was borne out of economics around the beginning of the 20th century. As the function gained momentum, and developed through the first three quarters of the twentieth century, the focus was on transactions and exchanges. However, the development of marketing as a field of study and practice is undergoing a re-conceptualization in its orientation from transactions to relationships (Webster, 1992). The emphasis on relationships as opposed to transaction based exchanges is likely to redefine the domain of marketing (Sheth, Gardener and Garett, 1988). Indeed, the emergence of a relationship marketing school of thought is imminent given the growing interest of marketing professionals in the relational paradigm.

The paradigm shift from transactions to relationships is related to the return of direct marketing both in business-to-business and business-to-consumer markets. As in the pre-industrial era once again direct marketing, albeit in a different form, is becoming popular, and consequently so is the relationship orientation. When producers and consumers directly deal with each other, there is a larger potential for emotional bonding that transcends economic exchange. They can understand and appreciate each others' needs and constraints better, are more inclined to cooperate, and thus, become more relationship oriented. This is in contrast to the exchange direction of the middlemen (sellers and buyers). To the middlemen, especially the wholesalers, the economics of transactions are more important, and therefore, they are less emotionally attached to products. Indeed, many middlemen do not physically see, feel, touch products but simply act as agents. The disconnection of the producers from the users was a natural outgrowth of the industrial era. On the one hand, mass production forced producers to sell through middlemen, and on the other, industrial organisations, due to specialization of corporate functions, created specialist purchasing departments and buyer professionals, thus separating the clients from the producers. However, today's technological advancements that permit producers to interact directly with large numbers of users, and because of a variety of organisational development processes, such as empowerment and total quality programs, direct interface between producers and users has returned in both consumer and industrial markets, leading to a greater relational orientation among marketers. Academic researchers are reflecting these trends in marketing practice, and searching for a new paradigm of the discipline that can better describe and explain it.

RM attempts to involve and integrate customers, suppliers and other infrastructural stakeholders into a firm's marketing strategy and activities (McKenna, 1991; Shani and Chalasani, 1991). Such involvement results in interactive relationships with suppliers, customers or other value chain partners of the corporation. An integrative relationship approach assumes overlap in the plans and processes of the interacting parties and suggests close economic, emotional and structural bonds among them. It reflects interde- 
pendence rather than independence of choice among the parties; and it emphasizes cooperation rather than competition and consequent conflict among the marketing actors. Thus, development of RM points to a significant shift in the axioms of marketing: from competition and conflict to mutual cooperation, and choice independence to mutual interdependence.

The discipline of marketing grew out of economics, and the growth was motivated by lack of interest among the economists in the details of market behaviour, in particular those related to the functions of the middlemen (Bartels, 1976; Houston, Gassenheimer and Maskulka, 1992). It coincided with the growth in the number of middlemen and the importance of distribution during the industrial era.

Unlike mainstream economists of the late nineteenth century, who were more preoccupied with public policy and economic effects of market institutions, early marketing thinkers had operational interests. The process of marketing was thought to cause additional forms of utility including time, place and possession utilities to the consumer (Macklin, 1924).

Thus, marketing as a discipline got organized around the institutional school of thought, and its main concerns centred around the tasks performed by wholesalers and retailers as marketing institutions.

Although the institutional thought of marketing was later modified by the organisational dynamics viewpoint, and marketing thinking was influenced by other social sciences, such as psychology, sociology and anthropology, exchange remained and still remains one of the central principles of marketing (Alderson, 1965; Bagozzi, 1974; Kotler, 1972). Formal marketing theory developed around the idea of exchange and exchange relationships, placing considerable emphasis on outcomes, experiences and actions related to transactions.

However, the relationship orientation of marketing is not an entirely a new phenomenon. If we look back to the practice of marketing before the 1900s, we find that relationship orientation to marketing was fairly prevalent. In short, current popularity of RM is a reincarnation of the marketing practices of the pre-industrial era in which producers and consumers interacted directly with each other and developed emotional and structural bonds.

The relationship orientation in marketing continued into the early years of the Industrial Revolution and the appearance of capitalism. Fullerton (1988) describes some of the efforts adopted by marketers during this period to build and maintain relationships with buyers. Marketing practices were also vastly individualized, relationship oriented and custom-made.

In the industrial era the market conditions gave rise to forceful selling and the development of marketing organisations that were willing to bear the risks and costs of inventory ownership and storage. Wholesalers, distributors and other marketing intermediaries assumed the role of middlemen who, on the one hand, stored the excess production of manufacturers, and, on the other hand, helped in locating and persuading more buyers to purchase. So vital became this function that early marketing thought was developed on the concept of distribution and the creation of time and place utilities. It was also around this time that the term 'marketing' itself was added to the lexicon as a noun opposed to its earlier use as a verb (Petrof, 1997). Among highly influential writers of the period Ralph Starr Butler and Arch W. Shaw are considered important to the evolution of the new marketing discipline. Ralph Butler (1882-1971) believed marketing was all 
about organisation, planning and the management of relationships. It was also in this period that theories developed that were later to become known as the commodity approach (focusing on all marketing actions involved in a particular product category), the institutional approach (focusing on describing the operations of a specialized type of marketing agency) and the functional approach (focusing on the purposes served by various marketing activities) (Wilkie and Moore, 2003). This period also gave rise to modern marketing practices, such as sales, advertising and promotion, for the purpose of creating new demand to absorb the oversupply of goods.

Thus emerged the transactions orientation of marketing whereby marketers became more concerned with sales and promotion of products and less with building enduring relationships. This shift was further accentuated during the Great Depression of 1929, when the oversupply of goods in the system heightened the pressure on marketers to sell their products. Thus the transaction orientation has been a major influence in marketing thought and scholastic research throughout the industrial era. During the height of the industrial period, marketing practices were aimed at supporting mass consumption. Developed out of the need to support the mass production machinery, the emphasis was aimed at increasing the sale of products and services. Marketing was considered successful only when it resulted in a transaction. Measures of marketing performance were linked, as is still the practice today in many corporations, to sales and market share.

Aided by the managerial school of marketing thought, two important developments occurred in the later period of the industrial era.

The first development was the marketer's realization that repeat purchase by customers was important, making it necessary to foster brand loyalty. Several marketing scholars also became interested in repeat purchase and brand loyalty behaviour as early as World War II (Churchill, 1942; Womer, 1944; Barton, 1946). This research was further advanced in the buyer behaviour theory of Howard and Sheth (1969), wherein they examined repeat purchase behaviour and brand loyalty. In order to achieve a brand image, brand differentiation and effective advertising, different marketing techniques emerged. In a seminal work, McCarthy presented the 'marketing mix' in the framework of the '4Ps model of marketing' (price, product, promotion and placement). Although this concept retained many of the key elements of the functional school it did shift the perspective toward the marketing management approach. In this respect, the development of market segmentation and targeting became imperative tools for marketing planning. In the face of competition, marketers realized the benefits of focusing on specific groups of customers for whom they could tailor their marketing programs and effectively differentiate themselves from their competitors (Peterson, 1962).

The second significant change was the development of administered vertical marketing systems (McCammon, 1965), whereby marketers not only gained control over channels of distribution, but also developed means of blocking competitors from entering into these channels. Vertical marketing systems such as franchising permitted marketers to extend their representation beyond their own corporate limits to reach final customers (Little, 1970). These developments represented the recurrence of direct marketing and in maintaining a long-term relationship with consumers.

Post-industrial era has seen substantial development toward RM, both in practice and in managerial philosophy. Marketers started realizing the need to supplement a transaction-orientation with an orientation which showed additional concern for customers. It began with the advent of compound products, which gave rise to the systems selling 
approach. At the same time, some companies started to insist upon new purchasing approaches such as national contracts and master purchasing agreements, making major vendors develop key account management programs (Shapiro and Wyman, 1981). These measures forced intimacy and durability in the buyer-seller relationships. Instead of purchasing a product or service, customers were more interested in buying a relationship with a seller. The key account management program designates account managers and account teams that assess the customer's needs and then husband the selling company's resources for the customer's benefit. Key account programs reflect higher commitment of selling organisations toward their major customers. Such programs, concurrently, led to the foundation of strategic partnering relationships that have emerged under RM (Anderson and Narus, 1991).

The expansion of relationship orientation of marketing in post-industrial era is the rebirth of direct marketing between producers and consumers. The impact of technological revolution is changing the nature and activities of the marketing organisations. The current development and introduction of sophisticated electronic and computerized communication systems into society is making it easier for consumers to interact directly with the producers. Producers are also becoming more knowledgeable about their consumers by maintaining and accessing sophisticated internet databases that capture information related to each interaction with individual consumers, at no or very low cost. As a result, the functions formerly performed by the middlemen are now being undertaken by either the consumer or the manufacturers. Producers are building such systems that allow them to undertake quick responses with regard to manufacturing, delivery and customer service, reducing the need for inventory management, financing and order processing through middlemen. Also, consumers have less time and thus a condensed inclination to go to the store for every purchase. They are willing to undertake some of the responsibilities of direct ordering, personal merchandising, and product use related services with little help from the producers.

Hence, given the recent technological strides and consumer attitudes, some functions performed by middlemen may be entirely removed. Similarly, the rapid convergence of technologies, such as communication and computers, mandates that companies in such industries work on joint projects to leverage their combined resources and to share risks. Thus, inter-firm partnering and alliances is becoming increasingly popular and important.

Another major force driving the adoption of RM is the area of Total Quality Management (TQM) that lately revolutionized industry's perspectives regarding quality and cost. Most companies saw the value of offering quality products and services to consumers at the lowest possible prices. When companies embraced Total Quality Management to improve quality and reduce costs, it became obligatory to involve suppliers and customers in implementing the program at all levels of the value chain. This needed close working relationships with customers, suppliers and other members of the marketing organisation. Thus, several companies, such as Motorola, IBM, Xerox, Ford, AT\&T, etc., formed partnering relationships with suppliers and customers in order to practice TQM. Other programs such as Just-in Time (JIT) supply and Material-Resource Planning (MRP) also made use of the inter-reliant relationships between suppliers and customers (Frazier, Spekman and O'Neal, 1988).

In addition to this, another force is the growth of the service economy. As more and more organisations depend upon revenues from the services sector, RM becomes more and 
more established. One reason being that services are typically produced and delivered by the same institution. Service providers are usually involved in the production and delivery of their services. For instance, in the case of personal and professional services, such as consulting services, accounting services, and legal services, the individual producer of the service is also the service provider. In much the same way as the users of these services are directly engaged in obtaining and using the service thus, minimising or even eradicating the role of the middlemen. In such a situation, a greater emotional bond between the service provider and service user develops and the urge for maintaining and enhancing the relationship. It is therefore evident that RM is equally important for scholars and practitioners of services marketing (Berry 1983; Crosby and Stephens 1987).

Certain organisational changes have facilitated the augmentation of RM. Amongst these the most significant is the role definition of the members of the institution. Through a variety of changes in organisational processes, companies are now directly involving users of products and services in the purchase and acquisition decisions. For a considerable time, these functions were managed by the procurement department as a specialized function, with little or no input from the actual users of these products and services. Thus, the separation that existed between the producer and the consumer due to the existence of middlemen, acting as gatekeepers, is potentially bridged in many cases. Wherever such changes are being made, direct interaction and cooperative relationship between producers and users develop.

Finally, in the post-industrialization period the increase in competitive concentration is forcing marketers to be concerned with customer retention. As several studies have indicated, retaining customers is less expensive and perhaps a more sustainable competitive advantage than acquiring new consumers. Marketers are realizing that it costs less to retain customers than to compete for new ones (Rosenberg and Czepiel, 1984). On the supply side it pays more to develop closer relationships with a few suppliers than to build up more vendors (Spekman, 1988). In addition, several marketers are also concerned with keeping customers for life, rather than predominantly making a one-time sale (Cannie and Caplin, 1991).

In summary, relationship-orientation in marketing has staged a comeback. It was only during the peak of industrialization that marketing's orientation shifted toward a transactional approach. With the advent of middlemen, and the separation of producers and users, there was a superior transactions orientation. Industrialization led to a reversal in the relationship between supply and demand, when due to mass production efforts producers created excess supply of goods and were themselves preoccupied with achieving production efficiencies. Thus, they needed middlemen to service the consumer. The middlemen in turn, adopted a transactional approach as they were more interested in the economic benefits of exchange than the value of production and/or consumption. Now with one-to-one connection between the manufacturer and user, relationship orientation in marketing has returned.

In the era of RM, the roles of producers, sellers, buyers and consumers are blurring. Consumers are progressively becoming co-producers. Not only there is a not as much of a need for middlemen in the process, there is also less of a boundary between producers and consumers and other stakeholders in the value chain. In many instances, market participants jointly participate in design, innovation, production and consummation of goods and services. Sometimes these relationships and activities become so enmeshed 
that it is difficult to separate the marketing actors from one another. There is also a blurring of time and place boundaries. For example, Procter \& Gamble has assigned twenty of its employees to live and work at Wal-Mart's headquarters to improve the speed of delivery and reduce the cost of supplying P\&G goods to Wal-Mart's branch outlets (Kotler, 1994). It is therefore hard to distinguish the elements as well as the time of occurrence of exchange. In RM, organisational boundaries are hard to distinguish as companies are more likely to be involved in shared relationship with their stakeholders. Some of these activities relate to joint planning, co-production, co-marketing, co-branding, cocreation, co-invention etc. where the parties in the relationship bring their resources together for creating a greater market value.

In summary, we observe that a relational orientation to marketing existed until the early years of industrial development. It was only when mass production led to an oversupply of goods that marketers became transaction oriented. However, this transaction orientation in marketing is giving way to the return of relationship orientation. This re-emergence of RM has the potential for a new 'General Theory of Marketing' (Sheth, Gardener and Garrett, 1988), as its fundamental axioms better explain marketing practice.

\subsection{Definition of Relationship Marketing}

Although a clearer picture of RM is becoming evident in the framework of the above mentioned evolution of the concept we would like to determine, more specifically, what is meant by the term.

Despite considerable academic research and management interest, RM may still be regarded more as an 'umbrella philosophy' with several relational variations rather than as a wholly unified concept with strongly developed objectives. There are numerous published definitions on the concept and further other terms have been frequently used either as substitutes for RM, or to describe similar concepts. These include direct marketing, customer relationship management, micromarketing, one-to-one marketing, loyalty marketing and interactive marketing, to name but a few. In general, however, the major characteristic of these techniques are more transactional than relational in nature (Egan, 2008).

As stated above RM is not an independent philosophy but draws on conventional marketing principles (Gordon, 1998). This view implies that the basic focus upon customer needs still applies but that it is the way marketing is practiced that requires change. As $\mathrm{RM}$ is a descendant of traditional marketing a good starting point in developing a definition is to look at how marketing has traditionally been perceived. This view might be summed up using the Chartered Institute of Marketing's definition of marketing:

Marketing can be defined as the management process of identifying, anticipating and satisfying customer requirements profitably (CIM, 2005).

This definition of traditional marketing and others of similar nature emphasize above all the functional and process nature of traditional marketing and make no explicit recognition of the long-term value of the customer.

Berry was among the first to introduce the term 'relationship marketing' as a modern concept in marketing and suggested it to be defined as attracting, maintaining and enhancing consumer relationships (Berry, 1983). While recognising that customer acqui- 
sition was, and would still remain, part of marketer's responsibilities this viewpoint emphasized that a relationship view of marketing implied that maintenance and development were of equal or perhaps even greater importance to the company in the long run than customer acquisition. Due to the fact that customer retention is much more important than attracting new customers, companies pursuing RM principles design strategies to develop close and lifelong relationships with the most beneficial customers. By differentiating between customer types the RM concept further suggests, that not all customers or potential customers should be treated in the same way. RM, in contrast, saw the need to communicate in different ways dependent on customer's status and value.

This view of marketing also implied that suppliers were not alone in creating or benefiting from the value created by the corporation. Rather RM can be seen as an ongoing process of identifying and creating new value with individual consumers and then sharing the value benefits with them over the lifetime of the association (Gordon, 1988). This is due the fact that a higher customer value will raise customer satisfaction; thereby customer loyalty will be instilling, which, in turn, creates higher profit due to increased volume resulting from positive word-of-mouth and repeat purchases.

Thus the overall objective of RM is to facilitate and maintain long-term customer relationships, which leads to changed focal points and modifications of the marketing management process. The familiar superior objectives of all strategies are enduring unique relationships with customers, which cannot be imitated by competitors and therefore provide sustainable competitive advantages.

Most of the concepts, ideas and developments discussed briefly above are present in the following refined definition which describes the objectives of RM as to identify and establish, maintain and enhance and, when necessary, terminate relationships with customers and other stakeholders, at a profit so that the objectives of all parties involved are met; and this is done by mutual exchange and fulfilment of promises (Grönroos, 1994).

The growing interest in RM suggests a shift in the nature of marketplace transactions from discrete to relational exchanges, from exchanges between parties with no past history and future prospects to interactions between parties with a history and plans for upcoming interaction.

As Doyle noted, practitioners and marketers often made the mistake of seeing marketing as a functional discipline rather than an integrated business process (Doyle, 1995). In the following chapters and throughout the book relationship management ideas, concepts and perceptions will be explained and we will establish the importance of RM as an integrated management approach.

\subsection{Relationship Economics}

It is almost impossible to discuss RM without discussion of the concept of loyalty as it is frequently seen as an expected outcome of RM and the phrase 'loyalty marketing' is often used interchangeably with RM (Palmatier et al., 2006).

The frequent assumption is that, from whatever sources the loyalty is derived, it translates into an unspecified number of repeat purchases from the same supplier over a specific period. A comprehensive definition of loyalty in this context is: 'The biased (i.e. 
non-random) behavioural (i.e. re-visit), expressed over time, by some decision-making unit with respect to one [supplier] out of a set of [suppliers], which is a function of psychological (decision making and evaluative) processes resulting in brand commitment' (Bloemer and de Ruyter, 1998 cited by Egan, 2008).

According to Uncles, the espoused view is that consumers actively seek an involving relationship with their brand (product manufacturer, service supplier, brand owner or retailer), which in turn offers psychological reassurances to the buyer and creates a sense of belonging (Uncles, 1999). The proposed benefit of loyalty schemes, is having this sense of belonging reinforced. The goal of such programs is to establish a higher level of customer retention in profitable segments by providing increased satisfaction and value to customers.

Although RM and loyalty marketing have several common components (e.g. the use of information technology, customer knowledge and direct customer communications), it is questionable whether the connection is any deeper (Hart et al., 1999). Loyalty programs suggest that this view of relationship formation is more similar to a stimulusresponse function than anything resembling a relationship. Rarely are loyalty schemes more than a sophisticated sales promotions where the loyalty is to the program and not the brand. Consequently, loyalty schemes play a part in relationship maintenance but cannot be taken as proxy for the RM viewpoint (Pressey and Mathews, 1998).

One axiom of traditional marketing is the belief that self-interest and free competition are the key drivers of value creation. That axiom is challenged by relationship marketers who suggest that is mutual cooperation that delivers this value (Shet and Parvatiyar, 1995). However, the illusion that RM is unconcerned about profitability because of its above mentioned cooperative tenor is false. A paramount objective behind companies adopting an integrative relational strategy must, at least ultimately, be sustainable profitability. Even though in a relational exchange the focus is more concerned with the longer-term economic benefits profits remain important to all parties (Morgan, 2000).

Conventionally, the focus of traditional marketing has been on creating new customers. This rather 'offensive marketing strategy' included, in addition to acquiring completely new customers, attempting to attract dissatisfied customers away from competitors, particularly in periods of fierce competition (Storbacka et al., 1994). Although the acquisition of customers is important, it is only an intermediate step in the process of value creation. The first line of defence is its existing consumers (Kotler, 1992).

Therefore, RM emphasizes the proposition that, in addition to 'offensive strategies', companies need 'defensive strategies' as well which reduce customer fluctuation (Sorbacka et al., 1994). The logic behind this integrated approach can be illustrated using the metaphor of the leaky bucket (Figure 1.1). This stresses the importance of keeping customers while recognising that acquiring customers is, of course, the basis for having any customers to keep. In order to succeed, an enterprise must both have a constant flow of new customers and prevent consumer exit. To achieve sustainable profitability both strategies of acquisition and retention must be pursued in the framework of an integrative management process.

- Customer acquisition: Any decrease in the overall number of customers has profitability implications. As mentioned earlier, companies in the past concentrated on the consumer acquisition process. However, against the background of forecasted low or even negative population growth in many mature markets, intensified competi- 


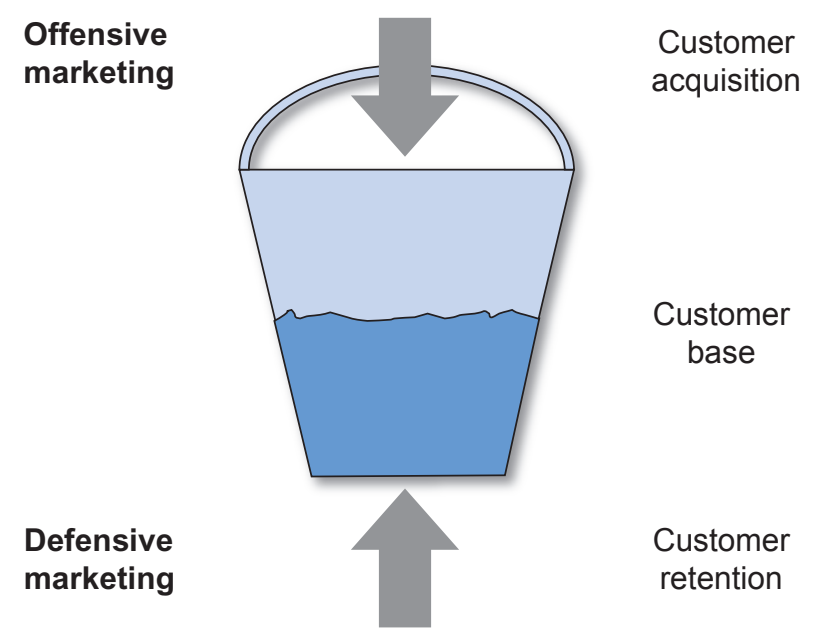

Source: Adapted from Egan, 2008

Figure 1.1: Leaky bucket theory

tive pressures and macro-economic crises customer acquisition in relative terms will become more difficult.

- Customer retention: Although RM requires a dual focus on both acquisition and retention strategies, it is the latter that is often given paramount prominence. In fact, it has become one of the underpinning convictions that RM fuels retention marketing first and acquisition marketing second. This view is generally supported by academics, many of whom further promote the concept by suggesting that customer acquisition is between five and ten times more expensive than customer retention (Gummesson, 1999). Although this widely accepted marketing maxim is a simplification, it has become widely accepted by an increasing number of enterprises that it is instrumental to keep existing customers satisfied rather than devote high levels of marketing effort to new customer acquisition (Barnes, 1994). To further strengthen this bias that the principal focus should be on retention, it is proposed that the longevity of relationships also provides additional profit potential stating the benefits are cumulative and that the longer the cycle continues the greater the company's financial strength. To put it in a nutshell, a major impetus for the development of RM has been a growing awareness of these potential long-term benefits.

Despite RM's concentration on retention, no company can practically hold on to all its customers. Total customer retention is never attainable as customers may switch to another product or service on the basis of criteria that may not be within the control of the enterprise. In addition to that, it may also be unprofitable to attempt to achieve a near total retention as the costs involved are likely to be prohibitive. Retention strategies should therefore not be aimed at keeping customers at any cost. Whereas in many industries it can be stated that the cost of acquisition exceeds that of retention, it is by no means a universal truth as it depends on company-specific factors and industries. 


\section{Economics of Retention Strategies}

RM can be regarded as an alternative to mass marketing and, as such, marketers' commitment to such strategies are only applicable when they are affordable and practical (Berry, 2000). Consequently, the economics of costly relational techniques must, in circumstances where acquisition and retention cost ratios are small, be closely examined. This is especially evident in the case of many costly loyalty schemes in which incentives to retention are costs that (if profitability is to be maintained) may lead to higher prices. The evidence that exists suggests that, in industries where recognizable high front-end costs (i.e. cost of personal selling, direct and indirect costs of detailed information gathering, supply of equipment, advertisement and other expenditure) are involved, these are drivers to relational strategies that promote customer retention over customer acquisition. Where acquisition costs are relatively low and/or where the real difference between acquisition and retention costs is marginal, the introduction of costly relational strategies may become a financial burden.

Retention economics are also promoted as a time-based type of competitive advantage through the suggestion that investment in long-term relationships brings long-term advantages (Egan, 2008). Relationship investment in this respect refers to the time, effort and resources that the supplier invests in building stronger investments (Palmatier et al., 2006). Gummerson has introduced the phrase 'return of relationships (ROR)' to describe the expectation that there would be a return on this investment. ROR can be defined as 'the long-term net financial outcome caused by the establishment and maintenance of an organisation's network of relationships' (Gummerson, 1999). The long-term orientation is often emphasized as it is believed that loyalty is cumulative as stated above.

Long-term benefits may be considered from two perspectives:

- relationship stages;

- the lifetime value of the consumer.

\section{Relationship Stages}

The definition of RM anticipates that, once a company begins thinking about individual customers, it must recognize that different customers are at different stages of relational development. Most importantly, it also suggests that each customer type (e.g. prospect, customer) should be treated in a different way like separate targeted messages and diverse value propositions. The appreciation of different relational stages in RM also includes the assumption that the higher the stage of development the greater the profitability to the business.

Dwyer et al. suggest a five-stage model where each phase represents a major transition in how parties in a relationship regard each other (Dwyer et al., 1987).

These are the following (Figure 1.2):

- Awareness is where one party realizes that the other party is a 'feasible exchange partner'. Interaction has not yet taken place although there may be 'positioning' by the parties.

- Exploration refers to the 'research and trial stage'. Partners consider obligations, benefits and burdens of the exchange.

- Expansion refers to the period where there is a continual increase in benefits obtained by partners and where they become progressively more interdependent. 


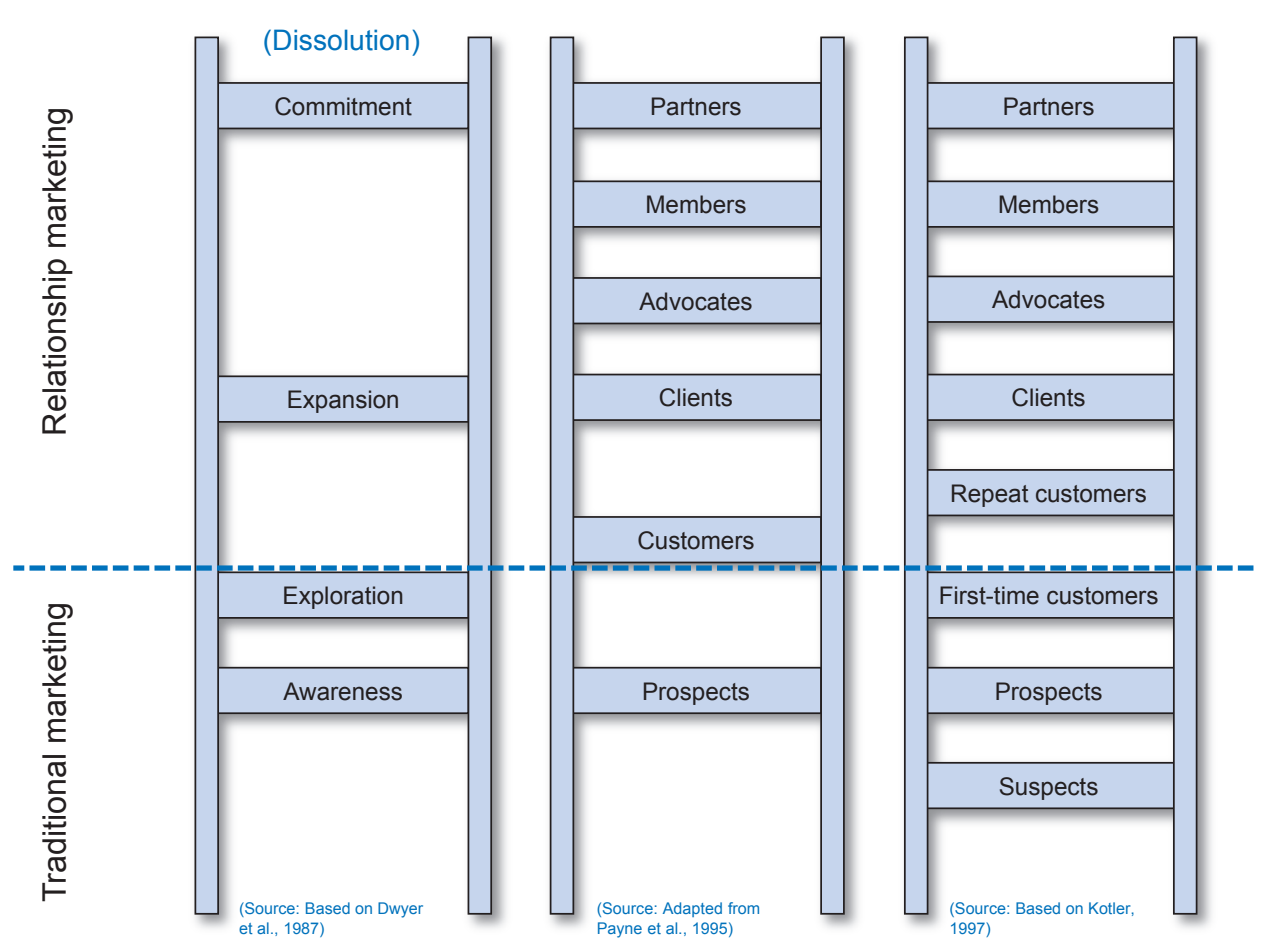

Source: Adapted from Egan, 2008

Figure 1.2: Relationship ladder and stages

- Commitment relates to the implicit or explicit promise of relational continuity between the parties.

- Dissolution implies that disengagement always remains a possibility in any relationship.

Other models suggest relational stages of customer development. The established concept of a 'ladder of loyalty' was adapted by Payne et al. to create a 'relationship ladder' (Payne et al., 1995) . Kotler also proposes a stages model.

All of the three models illustrated in Figure 1.2 promote the belief that, whereas traditional marketing's interest end with the sale, RM's interest extends beyond this to the development and enhancement of the customer relationship.

In the Kotler model the process begins with the suspects. Prospects are at a higher level and have in most cases given some indication that they are likely to purchase the goods or services on offer. Kotler differentiates between 'first-time' and 'repeat customers'. With repeat purchases the consumer has actual experience to persist. It is at this point that the relational marketer is seen to diverge from the traditional marketer, whose interest is seen to be predominantly in the single transaction. The essential task of the relational marketer from this point is to become skilful at moving customers to higher stages of relationship, with each stage representing a strengthening of the company's 
relationship with the customer (Kotler, 1997). The Kotler model suggests that the enterprise is looking to transform repeat customers into 'clients'. The further jump to the status of 'advocate' implies that the customer moves from being responsive to the company to becoming actively involved, most usually through word-of-mouth recommendation. 'Members' implies even greater affinity to the company while finally 'partnership' suggests a relationship on such a high level, that the customer becomes part of the valuecreation process.

\section{Lifetime Value of the Customer}

The increasing importance of RM was driven, in part, by the realization that people engage in relationships over lifetimes. The 'lifetime value' concept concludes that an enterprise should restrict taking a short-term view but rather should consider the income derived from that company's lifetime association with the consumer. In the framework of an integrative customer retention strategy a company should consequently project the value of individual customers over time rather than focus on customer numbers only (Dawes and Swailes, 1999).

Decisions concerning investment in relational approaches should be made on the basis of the customer's lifetime value. These investments may include those designed to enhance product or service quality in order to improve competitive positioning, or defensively to discourage defection to the competition. In the latter case the enterprise can create 'exit barriers' to promote retention by making switching costs high.

Switching costs are effectively barriers to exit from the relationship from the perspective of the customer. In this respect RM strategies are likely to be more successful if there are long time horizons and high switching costs. These are monetary and non-monetary costs that customers face when switching from one supplier to another. (Kinard and Capella, 2006). Switching costs may be created by the supplier, by the customer or by the relationship itself and include for example search costs, learning costs, emotional costs, financial costs and legal barriers (Egan, 2008).

\section{Relationship Longevity}

As stated above, customer retention leads to enhanced revenue, reduced costs and improved financial performance. The benefits that contribute to an entire 'life cycle of profits' from the customer are as follows (Figure 1.3):

- profit growth as a result of increased buying frequency and higher average purchases

- profit due to lower distribution and administration costs

- profit because of recommendation

- profit out of mark-ups

\subsection{Relationship Drivers}

Within the previous sections the concept of 'driver' toward relational strategy was already introduced and discussed, such as high customer acquisition costs and high exit barriers. In this part we will look at other drivers that appear to have an important bearing on the decision to develop a relationship marketing approach, in particular: 


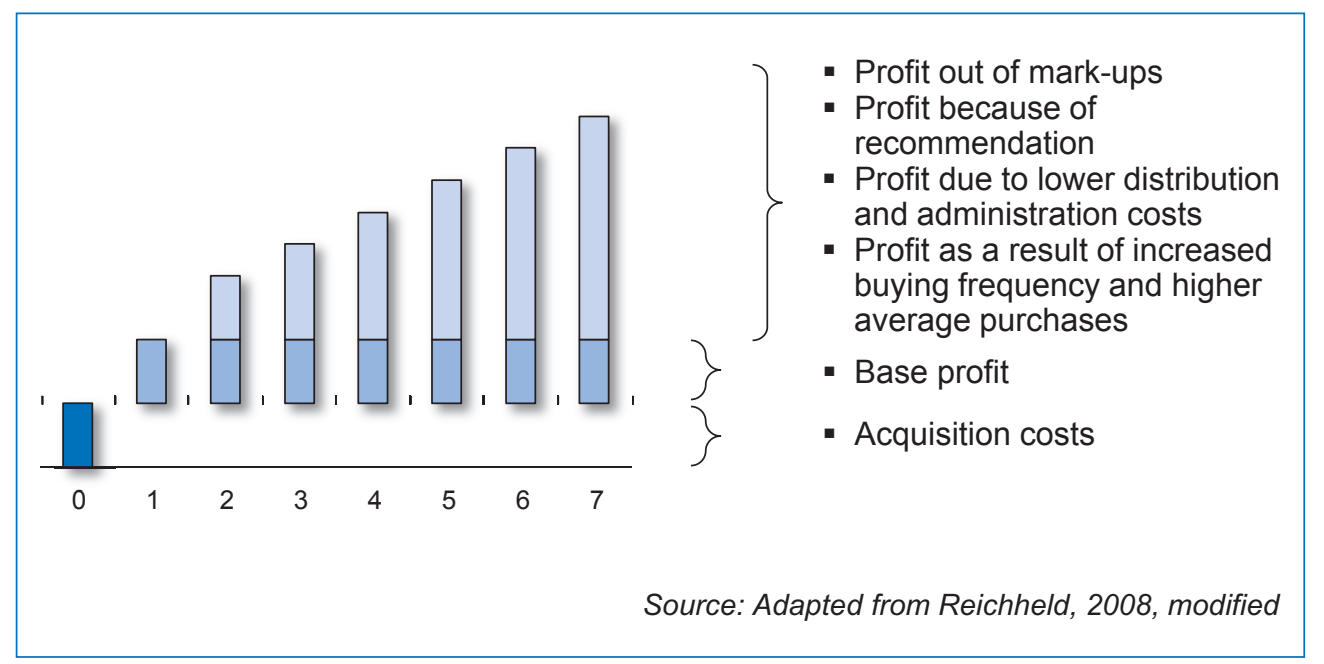

Figure 1.3: Profit growth over time

- risk, salience and emotion

- trust and commitment

- customer satisfaction (Egan, 2008)

- customer gratitude (Palmatier et al., 2009)

\section{Risk, Salience and Emotion}

As noted above, marketing academics and the relationship marketing literature suggest that the greater the perceived risk, the greater a customer's propensity to engage in relational-type behaviour and the more such strategies prove to be successful. A key reason why so-called high-risk purchases are likely to benefit from RM strategies is that a relationship is likely to lower the perceived risk as the customer gets to know the supplier. The existence of risk creates an opportunity for trust (Rousseau et al., 1998).

Salience may be regarded as the level of importance or prominence associated with the relationship. In situations characterized by high risk and salience, the consumer may enter the exchange with specific expectations associated with rather intense emotions. Consequently, a customer is intensively seeking specific reassurance and reduction of risk and uncertainty. These situations therefore appear to benefit from the closer ties and more frequent communication associated with RM strategies.

Products and services that generate emotions tend to be highly personalized and usually associated with self-worth. These categories include products such as clothing and services such as beauty. If the benefits associated with these products and services are emotionally important to consumers, then they are salient and the customer is likely to be risk averse. In these circumstances, relational strategies are instrumental to secure customer's loyalty and drive RM strategies (Egan, 2008).

\section{Trust and Commitment}

Trust creates benefits for the customer (e.g., relationship efficiency through decreased transaction costs) that in turn foster his or her commitment and loyalty to the relation- 
ship (Morgan, 2000). Therefore, confidence benefits/trust should positively influence the customer's commitment to the relationship. Morgan and Hunt define trust as confidence in the exchange partner's reliability and integrity (Morgang and Hunt, 1994).

Trust is seen as an important driver to both relationships and relationship enhancement in that it would seem to reduce risk perception. As well as generating cooperative behaviour, trust may (Rousseauch et al., 1998):

- reduce harmful conflict;

- decrease transactional costs (e.g. negating the need for constant checks);

- promote adaptive organisational forms (e.g. network relationships);

- facilitate the rapid formation of ad hoc groups;

- promote effective response to a crisis.

Berry (1995) suggested trust in a relationship reduces uncertainty and vulnerability, especially for so-called black-box-type services that are difficult to evaluate due to their intangible, complex, and technical nature. As such, he proposed that customers who develop trust in service suppliers based on their experiences with them have good reasons to remain in these relationships. This implies that loyalty to the firm will be greater when consumers have perceptions of trust or confidence in the service provider. Bitner (1995) echoed this proposition when she asserted that each service encounter represents an opportunity for the provider to build trust and thus increase customer loyalty.

Relationship commitment is suggested to be central to relationship marketing as well. Commitment implies the importance of the relationship to the parties and their desire to continue it (Wilson, 2000). It also suggests that both parties will be loyal, reliable and show stability in the relationship. As it usually takes time to reach a point where a commitment may be made, it may also imply a certain 'maturity' in a relationship (Bejou and Palmer, 1998). High levels of commitment are also associated with perceptions of future rewards, relationship identification, limited desire to seek out alternatives, the amount of effort expended in a relationship and the individuals assumed accountability (Grossmann, 1998).

What these descriptions of trust and commitment suggest is that, whatever the industry, it is important to build trust and commitment if the establishment of a relationship is the final goal.

\section{Customer Satisfaction}

Aside from confidence benefits/trust, relationship quality is generally considered to be composed of satisfaction and commitment. A high level of satisfaction provides the consumer with a repeated positive reinforcement, thus creating commitment-inducing emotional bonds. In addition, satisfaction is related to the fulfilment of customers' social needs, and the repeated fulfilment of these needs is likely to lead to bonds of an emotional kind that also constitute commitment (Hennig-Thurau and Klee, 1997). The relevance of satisfaction in gaining loyal customers and generating positive word-of-mouth is largely undisputed. Indeed, studies have found satisfaction to be a leading factor in determining loyalty (e.g. Rust and Zahorik, 1993). Similarly, satisfaction has been identified as a key driver in the generation of (positive) customer word-of-mouth behaviour.

Satisfaction is a psychological process of evaluating perceived performance outcomes based on predetermined expectations. Customers are, therefore, satisfied when their expectations of values are positively disconfirmed. In contrast, the greater the gap between 
the level of expectation and the matching of such expectations, the greater the level of dissatisfaction experienced by the consumer (Hutcheson and Moutinho, 1998).

Jones and Sasser suggest that the ability to listen carefully to the customer is at the heart of any successful strategy to manage consumer satisfaction. They propose the following categories of approach to this process (Jones and Sasser, 1995):

- Customer satisfaction indices are among the most accepted methods of tracking customer satisfaction. However, there is a problem with how questions are asked. Different results can be achieved with the same satisfaction survey dependent on how it was operationalised.

- Feedback includes notes, complaints and questions. This belongs to the most effective means of establishing what the customers regards as a satisfactory level of performance as it is based on actual performance and perception.

- Market research is a classic way of retrieving information but also one associated with high costs.

- Front-line personnel can provide a good way of listening to the customer as a result of their direct contact. The crucial factor here is how this information is fed back into the decision-making process.

- Strategic activities means to actively involve the customer in company decision-making and may be an effective way of establishing a sustainable relationship and create customers satisfaction through participation and co-creation.

\section{Customer Gratitude}

Finally, gratitude emerges as a key force that highly influences relationships across disciplines and represents the emotional core of reciprocity as well as a key motivating force in the development and maintenance of cooperative relational bonds (Bartlett and DeSteno, 2006). Extensive research suggests the inclusion of gratitude into RM claiming that gratitude represents an 'imperative force' that causes people to reciprocate the benefits they receive (Komter, 2004).

In addition to this, gratitude increases a customer's trust in the seller, both strengthening the quality of the relationship and positively affecting seller outcomes through Trust's influence on commitment (Palmatier et al., 2009). Against this background, feelings of gratitude and a history of gratitude-based behaviour appear to change customer's perceptions and evaluations of trust. Research by Palmatier et al. (2009) suggests that immediately after RM investments, customers may feel high levels of gratitude that result in their propensity to reciprocate although that propensity may decay over time. Consequently, managers should recognize the window of opportunity after a RM investment, during which they can 'collect' on feelings of gratitude. Thus, gratitude serves as a catalyst or trigger that promotes relationship development, which then influences social behaviour as long as the emotions lasts (Bartlett and DeSteno, 2006).

In summary, gratitude appears to enhance RM performance in three main ways (Palmatier, 2009):

- Customers engage in gratitude-based behaviours to satisfy their feelings of obligation in response to RM-induced feelings of gratitude.

- Increased levels of customer trust due to gratitude leverage customer commitment and thus enhance relational performance.

- Gratitude promotes the development of relationships by initiating cycles of reciprocation, which may have long-term positive effects on consumer behaviours. 


\section{Exhibit 1.1: OgilvyOne Worldwide for Kern}

\section{Company and Market Situation}

Founded in 1844 by Mechanikus Gottlieb Kern, Kern is a technology manufacturer specializing in precision scales. It is an independent, medium sized family business, in its sixth generation, registered in southern Germany. With over 170 years of experience and a steadfast commitment to quality, Kern is regarded as one of the leading specialist precision scales brand.

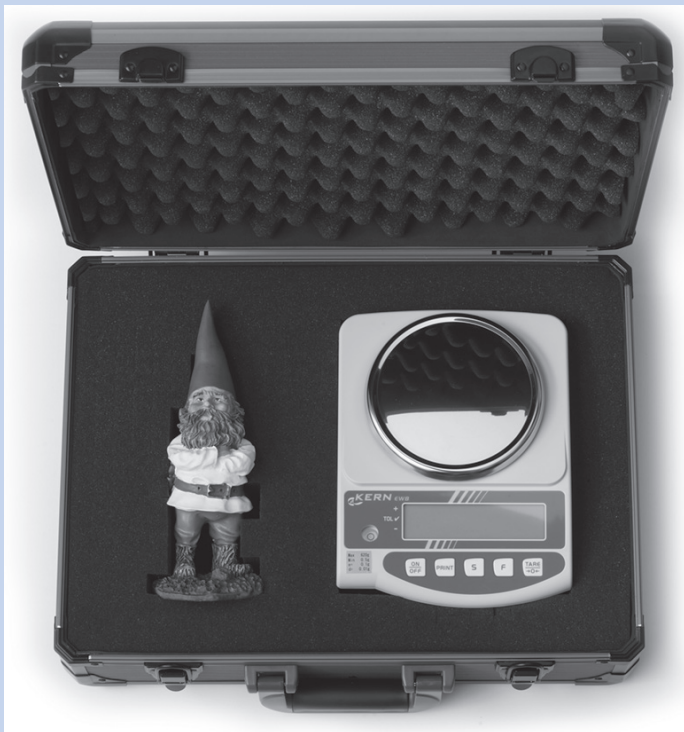

The target market for precision scales is diverse and global, ranging from school teachers to world-class scientists and pharmacists. The total annual value of the precision scales market is \$500 million in value and one million units in volume worldwide. It is growing at $2 \%$ per year. Kern's key competitors are MettlerToledo in Switzerland and Sartorius in Germany.

There are 200 scales in the product portfolio, ranging from low-cost school-type balances to high-end research instruments. The precision scales are priced at between \$100$\$ 10,000$. The scales are available for purchase either directly from Kern or via a distribution network of 1500 resellers operating in 50 countries.

Previous campaigns have demonstrated the precision of Kern technology. For example, Kern's redesigned corporate stationery features the weights of each element - from the weight of the business card, to the very ink used to print it. The advertising work has been recognised at various national and international advertising awards including Cannes Lions and D\&AD:

\section{Specific problem and task description}

The market for precision scales is highly commoditized with sales driven by equipment need, rather than brand familiarity. Individuals within Kern's target sectors have developed few independent views on quality, reliability or precision, relying mostly on functional specifications to discriminate between brands.

Kern wanted to differentiate itself and grow market share within the science and education sectors globally. With a small budget of $£ 24,000$, three key objectives were set: 
I. Drive sales to the education and science sectors by enhancing Kern's brand visibility and preference amongst these key markets.

II. Generate conversations internationally around gravity's influence on weight measurement - explaining the importance of Kern's unique selling proposition (USP), that is, calibrating scales for local gravity.

III. Raise awareness of Kern and its reputation for accuracy within and beyond its existing customer base and secure coverage outside of specialist media.

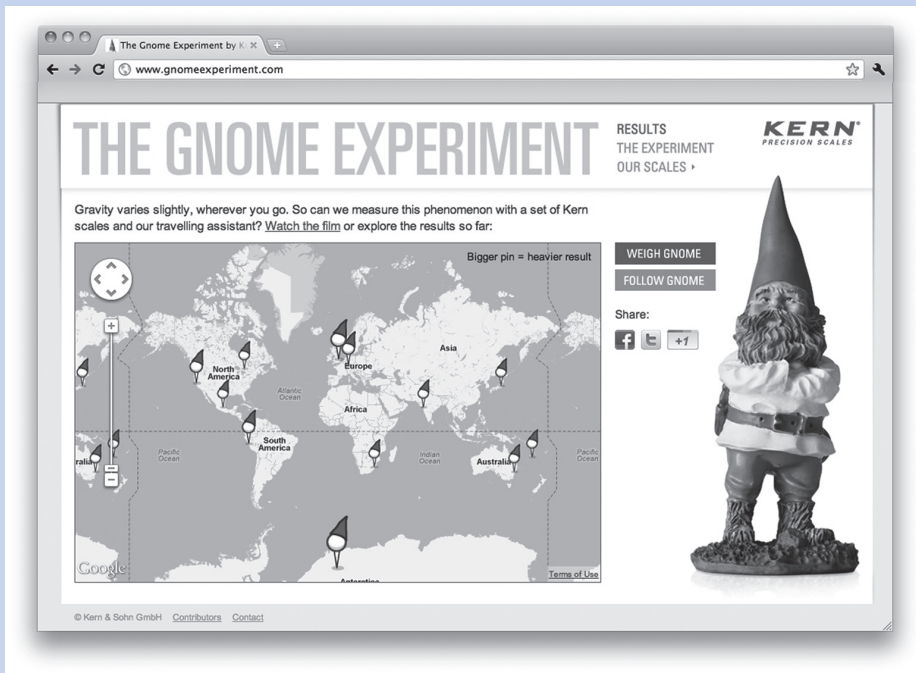

\section{Solution}

To place precision scales technology, measurement accuracy and Kern before the eyes of school teachers and laboratory technicians the world over, a campaign was needed that would capture the imagination of this diverse audience. The result was the Gnome Experiment - the world's first mass participation experiment that set out to prove the scientific theory that gravity varies from place to place and can affect weight.

The star of the experiment was a chip-proof garden gnome called Kern. Gnomes are famed for their love of travelling and originate from Bavaria, where Kern scales are manufactured. The gnome served to provide the campaign with a universally appealing personality.

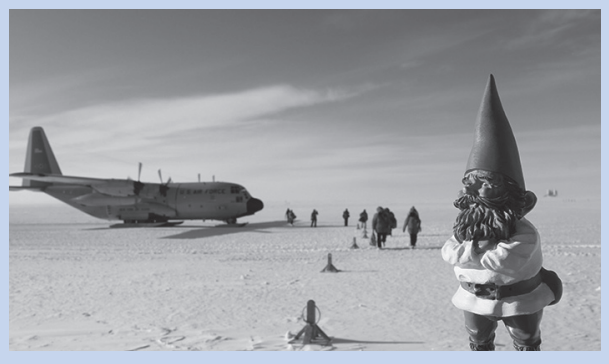

Kern customers and scientists around the world were emailed and invited to play a starring role in the experiment. A flight kit containing a set of Kern precision scales and the gnome was then circulated between the participants, each one weighing Kern, recording the results on the experiment website, taking photographic evidence and then sending him onto the next location. 
Scientists were charmed by the spirit of the experiment, happily escorting the gnome to landmarks such as to the top of mountains and to distant beaches, generating exotic, shareable imagery. Each world-famous institution Kern visited was a highly credible endorsement for the Kern brand. Kern's travels were documented on his own Tumblr blog and Twitter feed, which also explained the science behind the experiment.

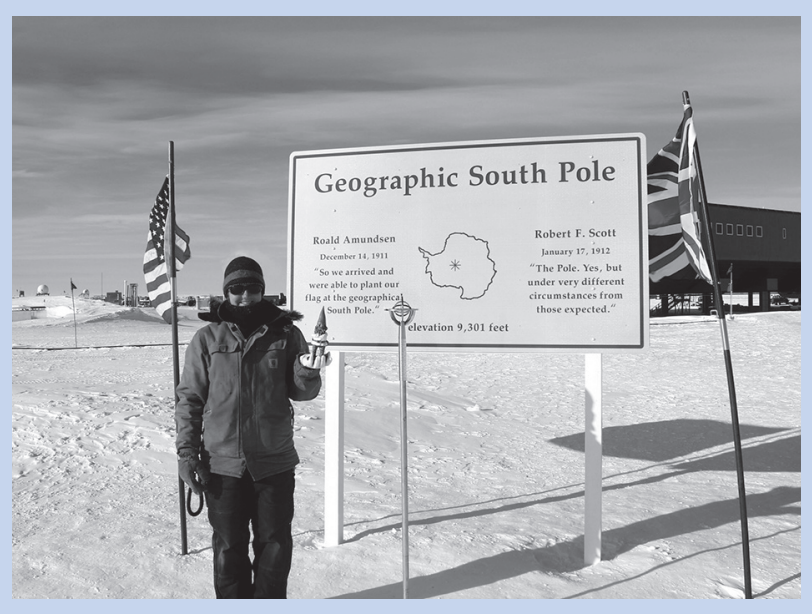

Once Kern reached the South

Pole, the story was released to the media. Social media news releases targeting global media as well as science and education influencers brought consumer and target business attention to Gnomeexperiment.com - requesting volunteers and engaging millions.

After just two weeks:

- Over 16,000 websites had linked to GnomeExperiment.com pushing Kern from page 12 to page one on Google.

- Over 355 million people saw the story across 152 countries.

- There was a $200 \%$ increase in traffic to the Kern e-catalogue, an $11 \%$ sales uplift and a 1,042\% ROI, and a $21 \%$ sales uplift across the entire Kern range after a month.

- The experiment has been added to the national school curriculum in several countries, putting Kern in front of a young audience.

- There was even a TED talk about the gnome's adventure.

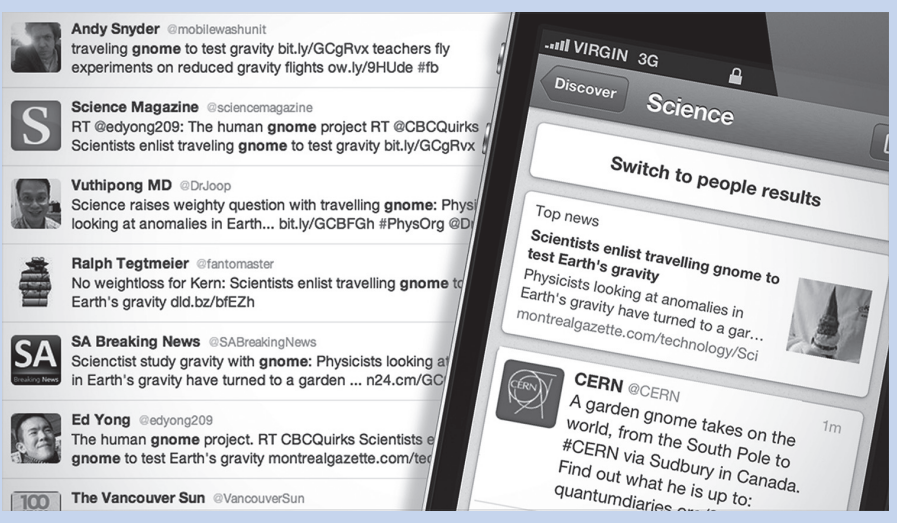




\subsection{Relationship Marketing as an Integrative Management Approach}

As Pels noted (1999) the debate regarding RM's place within marketing theory in the 1990s could be summed up as a choice between four alternative viewpoints:

- RM as a concept: By adding a relationship dimension to the marketing management approach the shortfalls identified in traditional marketing could be incorporated into the existing marketing paradigm.

- $R M$ as the dominant theory: Exchange Relationships should be regarded as a new marketing paradigm, suggesting that a paradigmatic shift had taken place in marketing from traditional marketing (Transactional marketing, TM) towards relationship marketing (RM).

- $R M$ as one marketing perspective: Exchange transactions and exchange relationships are separate paradigms and both paradigms separately coexist.

- $R M$ as an integral part of marketing: Transactional marketing (TM) and relationship marketing (RM) can coexist as part of the same marketing paradigm.

Despite RM'S recent promotion to the highest levels of marketing theory, however, there remain doubts as to whether companies should always find it suitable and/or profitable to develop relational strategies. Kotler, as one of the most prominent writers, for example, suggests that reports of the demise of traditional mass marketing are 'somewhat premature' and that companies such as Coca-Cola, Gilette and Kodak will continue primarily to practice traditional mass-marketing techniques (e.g. mass communication using mass media) into the foreseeable future (Kotler, 1997).

The logical consequence of this viewpoint is that some marketing activities may remain best handled through a transaction marketing approach. As Grönroos (1997, p. 408) suggests, 'the main thing is ... not whether a relational strategy is possible or not, but whether the firm finds it profitable, and in other respects suitable, to develop a relational strategy or a traditional strategy.' The implication is that, if enterprises cannot economically justify a relational approach, then they should retain or re-adopt a transactional strategy.

We suggest that transactional marketing and relational marketing can indeed coexist and that RM should not be considered simply as a replacement for TM strategies but as another - more integrative - perspective in marketing and the marketing management process. TM and RM take different marketing approaches to customers as outlined in table 1.1 .

This implies that RM is not a delimited phenomenon but an instrumental perspective in approaching marketing and as such part of the same paradigm extremes on a 'marketing strategy continuum' (Grönroos, 1995). Research suggests that a combination of TM and RM approaches are used by companies and that managers maintain a portfolio of strategy types (Brodie et al., 1997). Although the research conducted by Brodie et al. (1997) suggested that certain types of marketing (either TM or RM) are more common in some sectors than others, it dot not imply exclusivity. Their conclusion is that both transactional and relational marketing approaches can and do coexist. Purely relational strategies (either TM or RM) rarely exist. Consequently, it is better portrayed as a continuum of varying degrees of relational complexity. Exchanges, therefore, can be considered as falling somewhere along a spectrum ranging from the discrete to the relational. 


\begin{tabular}{|c|c|}
\hline Transactional marketing & Relationship marketing \\
\hline Orientation to single sales (transactions) & Orientation to customer retention \\
\hline Discontinuous customer contact & Continuous customer contact \\
\hline Focus on product features & Focus on customer value \\
\hline Short time scale & Long time scale \\
\hline Little emphasis on customer service & High emphasis on customer service \\
\hline $\begin{array}{l}\text { Limited commitment to meeting customer } \\
\text { expectations }\end{array}$ & $\begin{array}{l}\text { High commitment to meeting customer } \\
\text { expectations }\end{array}$ \\
\hline Quality as the concern of production staff & Quality as the concern of all staff \\
\hline $\begin{array}{l}\text { Marketing as the concern of marketing } \\
\text { staff }\end{array}$ & Marketing as the concern of all staff \\
\hline
\end{tabular}

Table 1.1: TM and RM compared

In this marketing continuum model RM is placed at one end of the spectrum. Here the primary focus would be on building relationships with consumers and other key stakeholders. At the other end of this continuum is TM, where the focus is more likely to be short term and based on one transaction at a time. Grönroos (1994) suggests that industry type may influence a company's position on the scale. He predicts that at one end is the end-user, consumer-goods market with a marketing mix approach based on discrete, transactional exchange and where customers are more sensitive to price than the development of any longer-term relationship. At this end of the continuum, traditional measures, such as the technical quality of the output and the monitoring of market share, are applied and internal marketing is not given paramount importance (Egan, 2008). At the other end are distribution channels, services and business-to-business marketers, who benefit from the application of relationship type strategies. The focus is rather on the long-term, with the use of an interactive approach based on the development, maintenance and enhancement of ongoing relationships. Price sensitivity is much less important and customers are seeking benefits which are delivered via the relationship with the supplier. The overriding measurement criteria is the quality of interactions with the customer and the successful management of the customer base (Egan, 2008). The role of internal marketing is of outstanding importance in this context (Figure 1.4).

What the concept of a marketing continuum suggests is that, although RM strategies may well be feasible for many products, services and markets, their application may be inappropriate for others. On the other hand, the adoption of RM strategies does not guarantee success. Grönroos (1995) notes that the more an enterprise moves to the right on the continuum, away from the transaction-type situation, the more the market expands beyond the product and the more has to be invested in RM.

Grönroos (1995) suggests that the marketing implications across the strategy continuum are elementary different concerning the following aspects:

- Dominant marketing orientation: RM implies that marketing should not be restricted to 'marketing mix activities' nor should it be only and wholly the responsibility of the marketing department. In TM, the marketing role of personnel outside of the marketing department is minor and elements such as advertisement and price promotions 


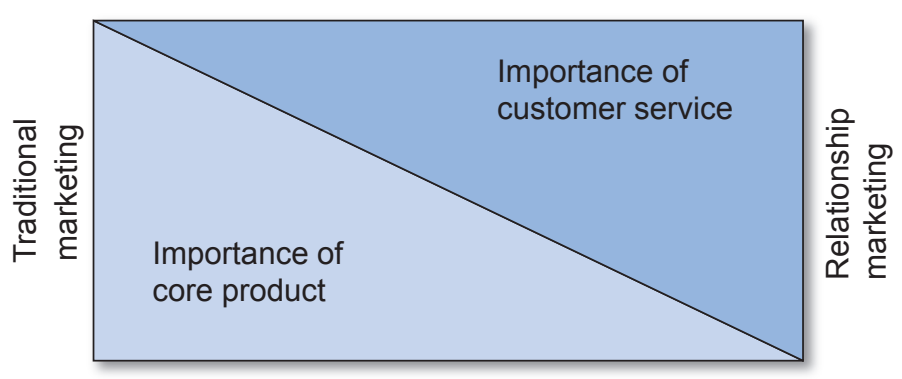

Source: Adapted from Grönroos, 1995, modified

Figure 1.4: The RM/TM continuum

are instrumental. In RM, these factors are also there but more as supporting activities to interaction and internal marketing strategies. Against this background, RM fosters a more integrative approach of marketing.

- Dominant quality function: In RM, although the technical quality has to be satisfactory, it is no longer the only quality dimension. Rather, all the interactions within the company support the quality perceptions of the customer.

- Customer information system: Companies pursuing TM strategies are likely to have little direct customer contact. TM relies instead on ad hoc customer satisfaction surveys and statistics for information about the behaviour of customers. An enterprise that applies RM strategies would monitor customer satisfaction by continuous contact and by directly managing its customer base (Egan, 2008).

- Interdependency between business functions: The level of interdependency between functions and departments is a business depends the strategy chosen by the company. In TM the marketing department takes care of the marketing function whereas in RM the interaction between marketing, operations, finance and other functions becomes critical to success.

- Role of internal marketing: Non-marketing employees and their marketing tasks are an important element of RM strategy. Enterprises operating such strategies have to take a proactive approach towards getting the commitment required to develop integrative marketing behaviour among all employees. The more people in the company are involved in marketing and a corresponding mind-set, the greater the need for internal marketing.

As we have discussed above, certain drivers may influence whether a company adopts a relational or transactional strategy. Table 1.2 enumerates these drivers (Table 1.2). Some of these drivers have been discussed in previous sections while others will be referred to in subsequent chapters in the framework of the marketing management process with special respect to a relationship approach.

Observation of marketing practice in international enterprises indicates that a hybrid managerial approach suggested by the above stated continuum concept is the most appropriate and differentiated response to prevailing market circumstances. Thus, there may exist a number of alternative marketing styles, any of which, depending on the customer-supplier relationship, may be more applicable (Chaston, 1998). Rather than suggesting that RM is taking over as the new marketing paradigm, it is more beneficial 
to accept it as part of marketing's tool box. It is therefore not TM versus RM or mass marketing versus customer-specific marketing that should be the argument (Kotler, 1997). A more adequate interpretation is that RM is not an appropriate strategy for all customers; moreover, multiple relationship marketing strategies may be necessary for different market segments and situations. The idea of a single, all-embracing, general unified theory of marketing is not suitable as strategies should, in a situational framework, be appropriate to given circumstances (Berry, 2000).

Against this background, the subsequent chapters will look at the marketing management process from the perspective of both relational and transactional approach suggesting that a company should in any case pursue an integrative marketing management approach with respect to the specific conditions the company is facing.

\begin{tabular}{|l|l|}
\hline Drivers promoting relational strategies & Drivers against using relational strategies \\
$\begin{array}{l}\text { High acquisition costs relative to retention } \\
\text { costs }\end{array}$ & $\begin{array}{l}\text { Acquisition/retention cost differential } \\
\text { minimal } \\
\text { High exit barriers }\end{array}$ \\
$\begin{array}{l}\text { Buoyant/expanding market } \\
\text { High risk/high salience products or services }\end{array}$ & Saturated market \\
High emotion involved in exchange & Low risk/low salience products or services \\
Satisfaction benficial to retention & Low emotion involved in exchange \\
\hline \multicolumn{2}{|c|}{ Repeat behaviour strategy beneficial } \\
\hline
\end{tabular}

Table 1.2: Drivers affecting strategic decision-making

\subsection{Fundamentals of Marketing Planning}

Marketing is the organisation function charged with defining customer targets and the best way to satisfy their needs and wants competitively and profitably. Because consumers and business buyers face an abundance of suppliers seeking to satisfy their every need, companies and not-for-profit organisations cannot survive today by simply doing a good job. They must do an excellent job if they are to remain in the increasingly competitive global marketplace. Many studies have demonstrated that the key to profitable performance is knowing and satisfying target customers with competitively superior offers. This process takes place today in an increasingly global, technical, and competitive environment.

There are some key reasons why marketing planning has become so important.

Recent years have witnessed an intensifying of competition in many markets. Many factors have contributed to this, but amongst some of the more significant are the following (Hollensen, 2006):

- A growth of global competition, as barriers to trade have been lowered and global communications improved significantly.

- the role of the multinational conglomerate has increased. This ignores geographical and other boundaries and looks for profit opportunities on a global scale. 
- In some economies, legislation and political ideologies have aimed at fostering entrepreneurial and 'free market' values.

- Continual technological innovation, giving rise to new sources of competition for established products, services and markets.

The importance of competition and competitor analysis in contemporary strategic marketing cannot be overemphasized. Indeed, because of this we shall be looking at this aspect in more depth in later chapters. This importance is now widely accepted amongst both marketing academics and practitioners. Successful marketing in a competitive economy is about competitive success and that in addition to a customer focus a true marketing orientation also combines competitive positioning.

The Marketing Concept holds that the key to achieving organisational goals lies in determining the needs and wants of target markets, and delivering the desired 'satisfaction' more effectively and resourcefully than competitors (Hollensen, 2006).

Marketing planning is an approach adopted by many successful, market-focused companies. While it is by no means a new tool, the degree of objectivity and thoroughness with which it is applied varies significantly.

Marketing planning can be defined as the structured process of researching and analysing the marketing situations, developing and documenting marketing objectives, strategies, and programs, and implementing, evaluating, and controlling activities to achieve the goals. This systematic process of marketing planning involves analyzing the environment and the company's capabilities, and deciding on courses of action and ways to implement those decisions (Jobber and Fahy, 2009). As the marketing environment is so changeable that paths to new opportunities can open in an instant, even as others become obscured or completely blocked, marketing planning must be approached as an adaptable, ongoing process rather than a rigid, static annual event.

The outcome of this structured process is the marketing plan, a document that summarizes what the marketer has learned about the marketplace and outlines how the firm plans to reach its marketing objectives. In addition, the marketing plan not only documents the organisation's marketing strategies and displays the activities that employees will implement to reach the marketing objectives, but it entails the mechanisms that will measure progress toward the objectives and allows for adjustments if actual results take the organisation off course (Hollensen, 2006).

Marketing plans generally cover a 1-year-period, although some may project activities and financial performance further into the future. Marketers must start the marketing planning process at least several months before the marketing plan is scheduled to go into operation; this allows sufficient time for thorough research and analysis, management review and revision, and coordination of resources among functions and business units.

Marketing planning inevitably involves change. It is a process that includes deciding currently what to do in the future with a full appreciation of the resource position; the need to set clear, communicable, measurable objectives; the development of alternative courses of action; and a means of assessing the best route towards the achievement of specified objectives. Marketing planning is designed to assist the process of marketing decision making under prevailing conditions of risk and uncertainty.

Above all the process of marketing planning has a number of benefits (Hollensen, 2006):

- Consistency: The individual marketing action plans must be consistent with the overall corporate plan and with the other departmental or functional plans. 
- Responsibility: Those who have responsibility for implementing the individual parts of the marketing plan will know what their responsibilities are and can have their performance assessed against these plans. Marketing planning requires management staff to make clear judgmental statements about assumptions, and it enables a control system to be designed and established whereby performance can be assessed against pre-defined criteria.

- Communication: Those implementing the plans will also know that the overall objectives are and how they personally may contribute in this respect.

- Commitment: Assuming that the plans are agreed upon by those involved in their implementation, as well as by those who will provide the resources, the plans do stimulate a group commitment to their implementation, and ultimately lead to better strategy-implementation.

Plans must be specific to the organisation and its current situation. There is not one system of planning but many systems, and a planning process must be tailor-made for a particular firm in a specific set of conditions.

Marketing planning as a functional activity has to be set in a corporate planning framework. There is an underlying obligation for any organisation adopting marketing planning systems to set a clearly defined business mission as the basis from which the organisational direction can develop.

Without marketing planning, it is more difficult to guide research and development (R\&D) and new product development (NPD); set required standards for suppliers; guide the sales force in terms of what to emphasize, set realistic, achievable targets, avoid competitor actions or changes in the marketplace. Above all, businesses which fail to incorporate marketing planning into their marketing activities may therefore not be in a position to develop a sustainable competitive advantage in their markets (Hollensen, 2006).

\section{The Main Stages in Developing a Marketing Plan}

Marketing planning is a methodical process involving assessing marketing opportunities and resources, determining marketing objectives, and developing a plan for implementation and control.

Marketing planning is an ongoing analysis/planning/control process or cycle (see Figure 1.5). Many organisations update their marketing plans annually as new information becomes accessible.

Once built-in, the key recommendations can then be presented to key stakeholders within the organisation. The final task of marketing planning is to summarize the relevant findings from the marketing analysis, the strategic recommendations and the required marketing programs in a report: the written marketing plan. This document needs to be concise, yet complete in terms of presenting a summary of the marketplace and the business's position, explaining thoroughly the recommended strategy and containing the detail of marketing mix activities. The plan should be informative, to the point, while mapping out a clear set of marketing activities designed to satisfactorily implement the desired target market strategy (Hollensen, 2006).

Figure 1.5 illustrates the several stages that have to be gone through in order to arrive at a marketing plan. Each of the stages illustrated here will be discussed in more detail later in this chapter and in later sections of the book. 


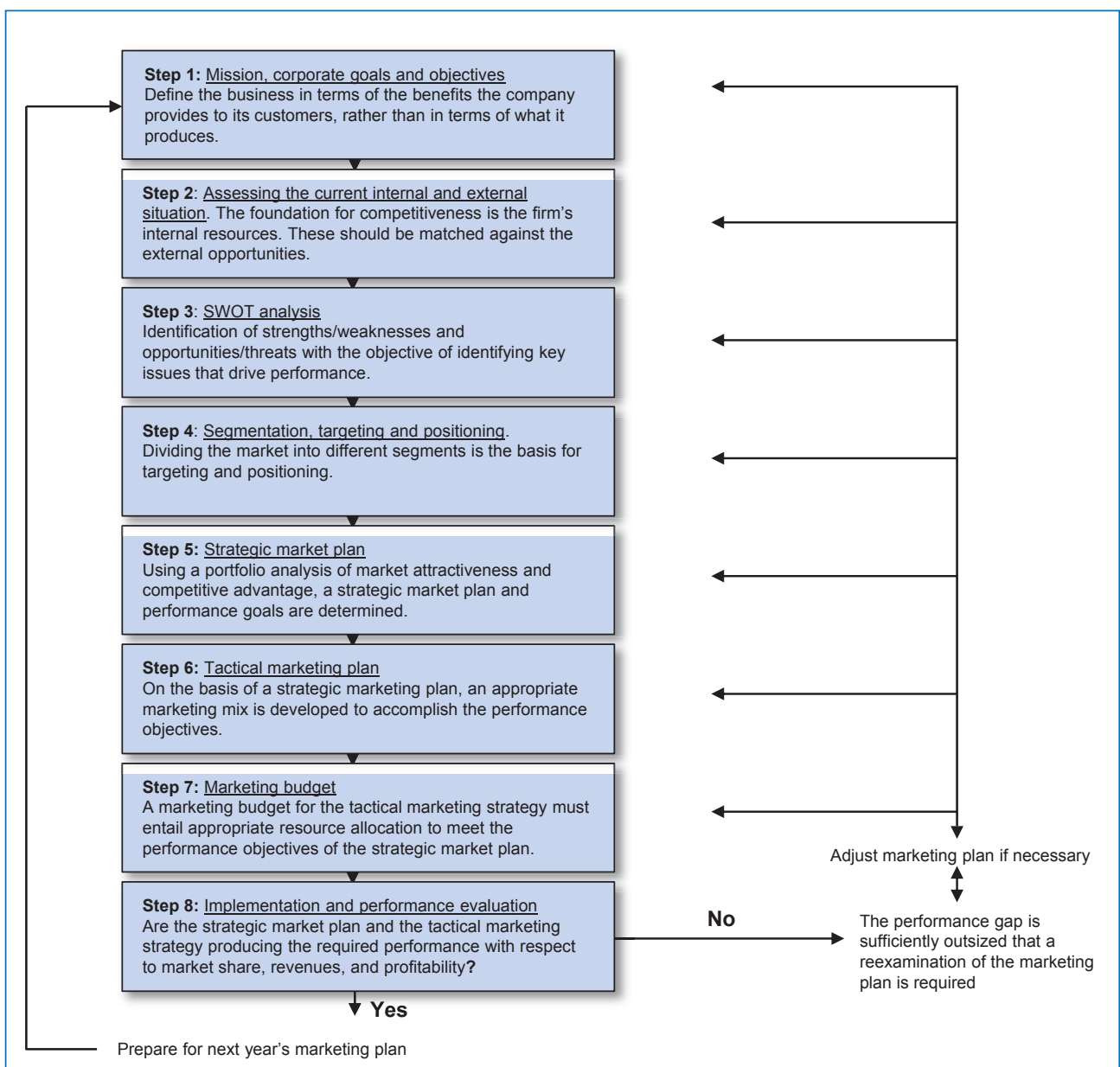

Source: Adapted from Hollensen, 2006, modified

Figure 1.5: The stages of building a marketing plan

As illustrated in Figure 1.5 the development of a marketing plan is a process, and each step in the process has a structure that enables the marketing plan to evolve from abstract information and ideas into a tangible document that can easily be understood, evaluated, and implemented. The following section is devoted to an in-depth discussion of each step in this process (Gilmore et al., 2001; Day, 2002).

\section{Step 1: Mission, Corporate Goals and Objectives}

An organisation's mission can be described as a broadly defined, enduring statement of purpose that distinguishes a company from others of its type (Ackhoff, 1987). It is enduring and specific to the individual organisation and tells what the organisation hopes to accomplish and how it plans to achieve this goal. This expression of purpose provides management with a clear sense of direction. 
The corporate mission statement needs comprehensive considerations by top management to establish the business, which the company is really in and to relate this consideration to future business intentions. It is a general statement that provides an integrating function for the business, from which a clear sense of business definition and direction can be derived.

This stage is often overlooked in marketing planning, and yet without it the plan will lack a sense of contribution to the development of the entire enterprise. By deriving a clear mission statement, boundaries for the 'corporate entity' can be conceived in the context of environmental trends that influence the company (Hollensen, 2006).

It is useful to establish the distinctive competences of the organisation and to focus upon what customers are buying rather than upon what the company is selling. This will assist in the development of a marketing oriented mission statement. A clear mission statement should include the customer groups to be served the consumer needs to be served and the technologies to be utilized.

Essentially, four characteristics are associated with an effective mission statement (Day, 1999):

- First, it must be based on a solid comprehension of the business, and the vision to foresee how the forces influencing its operations with alter in the future.

- Second, the mission should be based upon the deep personal conviction and motivation of the founder or leader, who has the ability to make his or her vision transmittable. An example is Google's mission to organize all the world's information and make it universally accessible and useful. Consequently, the mission must be shared throughout the organisation.

- Third, effective mission statements should instil the strategic intent of winning throughout the organisation. This helps to create a sense of common and shared purpose.

- Finally, mission statements should be enabling. Managers should believe they have the freedom to make decisions about the strategy. The mission statement provides a framework within which managers decide which opportunities and threats to address, and which to disregard.

The general purpose expressed in the organisation's mission statement must be translated into more specific guidelines as to how these general intentions will operate. Organisations and the people who manage them tend to be more productive when they have established standards to motivate them, specific directions to guide them, and stated achievements levels against which to assess their performance.

\section{Step 2: Assessing the Current Internal and External Situation}

The situation analysis attempts to provide answers to the following questions:

- 'Where are we now?'

- 'How did we get here?'

- 'Where are we heading?'

Answers to these key questions depend upon an analysis of the internal and external environment of a business (Jobber, 2010). Thus, the situation analysis encompasses the forces that shape market attractiveness, competitive position, and present performance. 
The basis for competitiveness is the firm's internal resources, capabilities and competences (Chapter 2 in this book). These should be matched with the external opportunities (Chapter 2 in this book), and altogether it sums up to step 3 - the SWOT analysis.

\section{Step 3: SWOT Analysis}

A SWOT analysis is a structured tool to evaluating the strategic position of a company by identifying its strengths, weaknesses, opportunities and threats. The subsequent steps will be only as good as the situation analysis and key performance issues that are uncovered in the situation and SWOT analysis.

In assessing current situations, SWOT analysis attempts to identify one or more strategic relationships or match-ups between strategic business units (SBU) current strengths or weaknesses and its present or future opportunities and threats. Corporations face strategic windows in which key requirements of a market and the particular competencies of the organisation best fit together. Identifying these limited time periods is a rationale for employing a SWOT analysis.

The tool provides a simple method of synthesizing the results of the internal and external analysis undertaken in step 2.

Strengths are the bases for building company competences and finally competitiveness. An internal organisational check attempts to ascertain the type and degree of each SBU's strengths and weaknesses. By recognising their special capabilities and limitations, firms are better able to adjust to the external environmental conditions of the marketplace. In this respect, it is of key importance to always question the strengths identified for their impact on customer satisfaction.

'Know yourself and your competence' is the basic tenet that guides this assessment of the abilities and deficiencies of the organisation's internal operations. It is also the basic tenet in the so-called Resource Based View (RBV), which will be further discussed in Chapter 2.

All businesses do have weaknesses. Successful businesses try to minimise their shortcomings. A weakness can be any business function or operation that is not able to resist external forces or withstand attack. A weak business function or operation is one that is deficient or inferior in its ability to reap the benefits presented by an external opportunity. Weaknesses are most viewed in comparative terms; a company has a weakness when it is unable to perform a business function or conduct a business operation as effectively and efficiently as its competitors (Hollensen, 2006).

The internal factors that may be viewed as strengths or weaknesses depending upon their impact on the organisation's positions (they may represent a strength for one organisation but a weakness, in relative terms, for another), may include all of the four elements of the marketing mix, as well as other functions such as personnel, finance etc..

The second part of a SWOT analysis involves the organisation's external environments. This environmental scanning process involves the opportunities and threats that are part of a SWOT analysis. The external factors, which again may be threats to one organisation whereas they offer opportunities to another, may include factors such as technological change, legislation, and socio-cultural changes, as well as changes in the marketplace or competitive position.

Opportunities are unsatisfied customer needs that the organisation has a good chance of meeting successfully. For an environmental occurrence to be considered an opportunity 
by a particular business, a favourable juncture of circumstances must exist. A unique business strength must fit an attractive environmental need in order to create a high probability of a successful match, as when a low-cost producer identifies an unserved market of low-income consumers. Good opportunities are needs that the company can satisfy in a more complete fashion than can existing competitors. In this context it has to emphasized that these opportunities are indeed external factors which are not controllable by the company such as demographic change, the fitness trend etc.

Threats are finally aspects of the external environment that create challenges posed by an unfavourable trend or development that would lead, in the absence of defensive marketing action, to lower sales or profit (Kotler et al., 2006).

Once a SWOT analysis has been completed management has to evaluate how to turn weaknesses into strengths and threats into opportunities. For example, a perceived weakness in customer focus might suggest the need for extensive staff training to create a new strength. Because these activities are designed to convert weaknesses into strengths and threats into opportunities they are called conversion strategies.

Another option provided is to match strengths with opportunities. An example of a company that successfully matched strengths with opportunities in the UK clothing retailer Next, which identified an opportunity in the growing demand for telemarketing services. One of the company's strengths was the fact that it had run its own call centres for more than a decade to service its own home shopping operation. As a result, Next has created a profitable business running call centres for other organisations (Jobber, 2010). These activities are called matching strategies.

The SWOT-analysis is just one tool to assess the current situation. It has its own weaknesses in that it tends to persuade companies to compile lists rather than to think about what is really important to their business. It also presents the resulting lists without clear prioritization, so that, for example, weak opportunities may appear to balance strong threats.

The aim of any SWOT analysis should be to identify potential 'strategic windows' and isolate what will be important to the future of the organisation and that subsequent marketing planning will address.

\section{Step 4: Segmentation, Targeting and Positioning}

In addition to analyzing the environment, marketers need to analyze their markets and their customers, whether consumers or businesses. This means looking closely at market trends, changing customer behaviour, product demand and future projections, buying habits, needs and wants, customer attitudes, and customer satisfaction.

Marketers have to apply their knowledge of the market and customers - acquired through research - to determine which parts of the market, known as segments, should be targeted for marketing activities as marketing is not about chasing any customer at any price. A decision has to be made regarding those groups of customers respectively segments that are attractive to the business (Jobber, 2010). This implies dividing the overall market into separate groupings of customers, based on characteristics such as age, gender, geography, needs, behaviour, or other variables.

The purpose of segmentation is to group customers with similar needs, wants, behaviour, or other characteristics that affect their demand for or usage of the good or service being marketed. 
Once the market has been segmented, the next set of decisions focuses on targeting, including whether to market to one segment, to several segments, or to the entire market, and how to cover these segments. The company also needs to formulate a suitable positioning, which means using marketing to create a competitively distinctive place (position) for the brand or product in the mind of targeted customers. This positioning must effectively set the product apart from competing products in a way that is meaningful to customers.

\section{Step 5: Strategic Market Plan (Marketing Strategy)}

At this point in the marketing planning process, the company has examined its current situation, looked at markets and consumers, set objectives, and identified segments to be targeted and an appropriate positioning. Now management can create the marketing strategies, effectively combining the basic marketing mix tools of product, place, price, and promotion, enhanced by service strategies to build stronger customer relationships.

Marketing strategies must be consistent with the organisation's overall corporate goals and objectives. As marketing objectives are essentially about the match between products and markets they must be based on realistic customer behaviour in those markets.

To be most effective, objectives must be measurable. The measurement may be in terms of sales volume, turnover volume, market share, or percentage penetration of distribution outlets. As it is measured, it can, within limits, be unequivocally monitored and corrective action taken as appropriate. Usually marketing objectives must be based, above all, on the organisation's financial objectives; financial measurements are converted into the related marketing measurements. An example of a measurable marketing objective might be 'to enter market $X$ with product $Y$ and capture 15 percent of the market by value within the first three years.'

In principle, the strategic market plan describes how the firm's marketing objectives will be achieved. It is essentially a pattern or plan that integrates an organisation's major goals, policies, and action sequences into a cohesive whole. Marketing strategies are generally concerned with the 4Ps:

1. Product strategies

- Developing new products, repositioning or re-launching existing ones, and scrapping old ones

- Adding new features and benefits

- Balancing product portfolios

- Changing the design or packaging

2. Pricing strategies

- Setting the price to skim or to penetrate

- Pricing for different market segments

- Deciding how to meet competitive pricing

3. Promotional strategies

- Specifying the advertising platform and media

- Deciding the public relations brief

- Organizing the sales force to cover new products and services or markets

4. Place distribution strategies

- Choosing the channels

- Deciding levels of customer service 
One often-overlooked aspect of the marketing strategy is timing. Choosing the best time for each element of the strategy is often vital. Sometimes, taking the right action at the wrong time can be almost as bad as taking the wrong action at the right time. Timing is, therefore, an essential part of any plan and should normally appear as a schedule of planned activities (Hollensen, 2006).

\section{Step 6: Tactical Marketing Plan}

The next step in the marketing planning process is the development of a tactical marketing plan to put the strategic market plan into operation. Although the overall marketing strategy to protect, grow, harvest, enter, or exit a market position is set by the strategic market plan, more-specific tactical marketing strategies need to be developed. Marketing managers have at their disposal four marketing tools with which they can match their products and services to customer's requirements. These marketing mix decisions consist of evaluations about price levels, the blend of promotional techniques, the distribution channels and the types of products to manufacture (Jobber, 2010).

Therefore, the firm's overall marketing strategies need to be developed into detailed plans and programs. Although these detailed plans may cover each of the 4Ps, the focus will vary, depending on your organisation's specific strategies. A product-oriented company will focus its plans for the 4Ps around each of its products. A market or geographically-oriented company will concentrate on each market or geographical area. Each will base its plans on the detailed needs of its customers and on the strategies chosen to satisfy these needs.

The most important element is the detailed plans, which spell out exactly what programs and individual activities will take place over the period of the plan (usually over the next year). Without these specified - and preferably quantified - activities the plan cannot be monitored, even in terms of success in meeting its objectives.

\section{Step 7: Marketing Budget}

The traditional quantification of a marketing plan appears in the form of budgets. The purpose of a marketing budget is to pull all the revenues and costs involved in marketing together into one comprehensive file. It is a managerial tool that balances what is needed to be spent against what can be afforded and helps make choices about priorities. It is then used in tracking the performance in practice.

Resources need to be allocated in a marketing budget based on the strategic and operational marketing plan. Without adequate resources, the tactical marketing strategies cannot succeed, and, as a consequence, performance objectives cannot be achieved.

Specifying a marketing budget is perhaps the most difficult part of the market planning process. Although specifying the budget is not a clear-cut process, there must be a logical connection between the strategy and performance objectives and the marketing budget.

Each area of marketing activity should be allocated to centres of responsibility. Indeed, as a key functional area of business the marketing budget is one of the key budgets to concentrate towards the total budgetary control system of the organisation.

In many organisations, budgeting is the transitional step between planning and implementation, because the budget, and allocated centres within it, will project the cost of 
each activity over the specified period of time, and also act as a guide for implementation and control (Hollensen, 2006).

\section{Step 8: Implementation and Performance Evaluation}

The best marketing plan is useless unless it 'degenerates into work' (Drucker, 1993, p. 128). Consequently, the business must design an organisation that has the capability of implementing the strategy and the tactical plan.

Once strategies and plans are implemented, the company needs to plan for ways to determine effectiveness by identifying mechanisms and metrics to be used to measure progress toward objectives. Most companies use sales forecasts, schedules, and other tools, to set and record standards against which progress can be assessed. By comparing actual results against daily, weekly, monthly, quarterly, and yearly projections, management can see where the firm is ahead, where it is behind, and where it needs to make adjustments to get back on the right path.

In the course of reviewing progress, marketers also should look at what competitors are doing and what the markets are doing so they can put their own outcomes into context.

To control implementation, marketers should start with the objectives they have set, establish standards for measuring progress toward those targets, measure the performance of the marketing programs, diagnose the results, and then take corrective action if results fail to measure up. This is the marketing control process. The control process is iterative; managers should expect to retrace their steps as they systematically implement strategies, assess the results, and take action to bring performance in line with expectations. Companies use this control process to analyse their marketing implementation on the basis of such measures as market share, sales, profitability, and productivity.

There are three main marketing planning approaches, in terms of involvement of the organisation as a whole. They are:

- Top-down planning: Here top management sets both the goals and the plan for lowerlevel management. While decision making may be immediate at the top level, implementation of the plans may not be as swift because it takes time for various units (division, groups, and departments) to learn about the plans and to reorganize their tasks accordingly to accomplish the new goals.

- Bottom-up planning: In this approach, the various units of the organisation create their own goals and plans, which are then approved (or not) by higher management. This can lead to more creative approaches, but it can also pose problems for coordination. More pragmatically, strategy all too frequently emerges from a consolidation of tactics.

- Goals-down-plans-up planning: This is the most common approach, at least among the organisations that invest in such sophisticated planning processes. Top management set the goals, but the various units create their own plans to meet these goals. These plans are then typically approved as part of the annual planning and budgetary process. 
Summary

This chapter has looked at the development of relationship marketing (RM) and the significant interest it has created among academics, consultants and practitioners alike. It examined the roots of RM and reviewed the perceived problems with traditional marketing in the light of changing and complex markets. A definition of RM was presented as a reference point upon which future analysis is based.

Loyalty as a concept close to the heart of RM was elaborated upon and it was suggested that loyalty schemes may play a part in relationship maintenance but cannot realistically taken as a proxy for the RM philosophy.

Additionally, this chapter investigated the arguments surrounding the costs of customer acquisition versus the costs of customer retention and summarized that whereas in many industries it can be stated that the cost of acquisition exceeds that of retention, this is always dependant on company and environment specific factors and not a universally applicable truth. The benefits of relationship longevity, including stages theories, the concept of lifetime value as well as the switching costs associated with relationship longevity where also discussed in this chapter.

A number of perceived drivers to relational and transactional strategies were discussed. The existence of high risk, high salience and, consequently, high emotion in an exchange transaction suggest that RM strategies would be beneficial as the customer may perceive that a close relationship is required in such situations.

The perceived need for trust and commitment in close relationships provided another indicator of situations where relational strategies may be successful.

The concept of customer satisfaction was examined and it was concluded, that the perceived need for positive customer satisfaction in a relationship may, in general, prove a reasonable driver of the benefits of relational strategies.

Furthermore, this chapter investigated the arguments for a 'strategy continuum'. It concluded that while RM may be beneficial in some situations, it may not be relevant to all. RM is to be best regarded not as a dominant and all-embracing marketing paradigm but as an instrumental and more integrative perspective in marketing. Consequently, the suggestion is made, that a strategy continuum exists with traditional marketing and relational marketing at either end. Any company, at any point in time, may adopt one or more of a 'hybrid' range of strategies that may be dominated by one or other end of the strategy continuum. The chapter suggests that although RM may not be a new marketing paradigm its approach can help marketers and non-marketers to adopt a more integrative perspective.

This chapter finally described marketing planning as the structured process companies use to research and analyse their marketing situation; develop and document marketing objectives, strategies, and programs and then implement, evaluate, and control marketing activities to achieve their marketing objectives. The marketing plan, which documents the results of the marketing planning process, serves as an important coordination function by helping to develop internal consensus, providing internal direction, encouraging internal collaboration, coordinating resource allocation, and outlining the tasks, timetable, and responsibilities needed to reach the marketing objectives.

There are many benefits to a good marketing plan. The process of market planning can lead a business to discovery of new market opportunities, to better utilization of assets and capabilities, to a well-defined market focus, to improved marketing productivity, and to a baseline from which to evaluate progress toward goals.

The eight broad steps in developing a marketing plan are:

1. Mission, corporate goals and objectives

2. Assessing the current internal and external situation

3. SWOT analysis

4. Segmentation, targeting and positioning 
5. Strategic market plan (marketing strategy)

6. Tactical/operational marketing plan

7. Marketing budget

8. Implementation and performance evaluation

The development of a marketing plan involves process and structure, creativity and form. The process begins with a broad view of market opportunities that encourages a wider consideration of many market opportunities. For each market opportunity, a strategic market objective is set, based on market attractiveness and competitive advantage attained or attainable in the market. For each market to be pursued, a separate situation analysis and marketing plan is required. The situation analysis enables the business to uncover key issues that limit performance. These key performance issues are the basic guidelines from which marketing strategies are developed.

With the marketing strategy and budget set, an estimate of market and financial performance metrics must be projected over a specified time frame. If the marketing plan fails to produce desired levels of performance, the marketing strategy needs to be re-examined.

\section{Questions for discussion}

1. What were the influences that led to the development of relationship marketing?

2. What are the major differences between traditional and relationship marketing?

3. What part do loyalty schemes play in relationship development?

4. What are the different cost drivers associated with customer acquisition and customer retention?

5. What are the potential advantages to be gained from long-term supplier-customer relationships?

6. What effect do switching costs have on a relationship?

7. Explain the association between risk, salience and emotion!

8. Explain the association between trust and commitment!

9. Take three companies with which you are familiar. Where would you place them on the hypothetical RM/TM continuum? What factors led to your decision to place them there?

10. How could businesses engaged in no market planning or in highly formalized market planning miss meaningful market insights?

11. What are the differences between marketing objectives and marketing strategies? What should marketing strategies cover?

12. What is the relationship between the mission statement and the SWOT analysis? What is the relationship between the mission statement and the firms objectives?

13. What is the role of a SWOT analysis in the marketing planning process? What is the role of key issues in the SWOT analysis?

14. Why is the development of a marketing budget so important to the success of the marketing plan?

15. What is the purpose of the performance evaluation? What role should it play in the successful implementation of a marketing plan?

16. In which ways may the organisation be involved in the marketing planning? 


\section{Case 1: Dräger}

\section{Establishing a system of strategic key performance indicators (KPIs) in order to be able to measure the performance of marketing and sales activities in the B2B}

Today new and increasingly demanding challenges are provided in the B2B marketing. In the development and global implementation of marketing plans, it is becoming increasingly important to analyze interactions in the right context and to establish KPIs to measure the proper planning, implementation, and performance of marketing measures.

Many companies are just beginning to look into this issue very slowly. Dräger recognized the relevance many years ago at an early time and started to guide its marketing and sales processes with the help of KPIs.

\section{About Dräger}

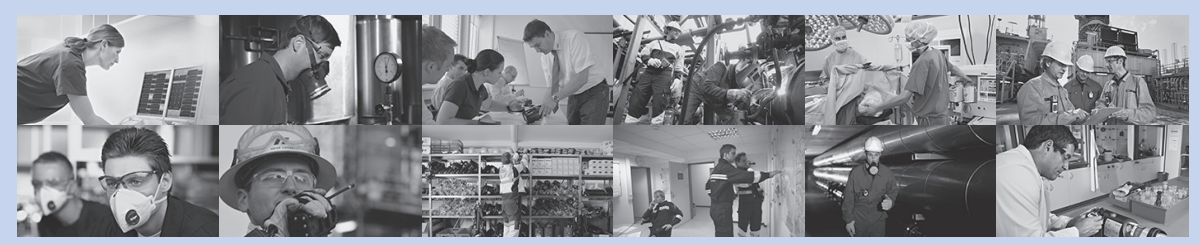

Dräger is an international leader in the fields of medical and safety technology. "Technology for Life" is the guiding philosophy. Whether in the operating room, in intensive care or emergency response services, Dräger products protect, support and save lives.

\section{Dräger. Technology for Life ${ }^{\circledR}$}

In the medical division Dräger develops, produces, and markets system solutions, equipment, and services for acute point of care (APOC). These include perioperative care (products and services connected to the operating room), critical care, and perinatal (neonatal) care, as well as emergency care.

Dräger's safety division focusses on personal protection, gas detection technology, and integrated hazard management. The portfolio includes stationary and mobile gas detection systems, personal protective equipment, professional diving systems, alcohol and drug testing devices, a varied range of training and services, and also projects such as entire fire training systems.

The family run company was founded in Lübeck, Germany, in 1889. Over the past five generations, Dräger has evolved into a publicly traded, worldwide group. The company's long-term success is based on the four key strengths of its value-driven culture: customer intimacy, professional employees, continuous innovation and a commitment to outstanding quality. 
Dräger has about 13,500 employees worldwide and is currently present in more than 190 countries. The company has sales and service subsidiaries in over 50 countries. Its development and production facilities are based in Germany, Great Britain, Sweden, the Czech Republic, South Africa, the USA, Brazil, and China.

\section{Two brand survey concepts help Dräger to better understand its target audiences: "DAYLIGHT" and "COLUMBUS"}

\section{How is the performance perceived by customers and potential customers?}

Several years ago the company was looking for growth. They decided to implement and properly monitor a few pertinent KPIs to convey information in an effective manner to anyone in the management wishing to interpret current status and progress.

As result they established a standardized global customer loyalty management approach with the goal to monitor the enhancement of customer awareness (attract new customers) and the level of customer binding (maintaining existing customers /customer satisfaction/loyalty).

In an accompanied long term concept of two global studies (so called "COLUMBUS" and "DAYLIGHT") along the entire Marketing funnel they map their activities from a moment the brand or product attract their consumer attention to the point of purchase and repurchase and designed their company internal model:

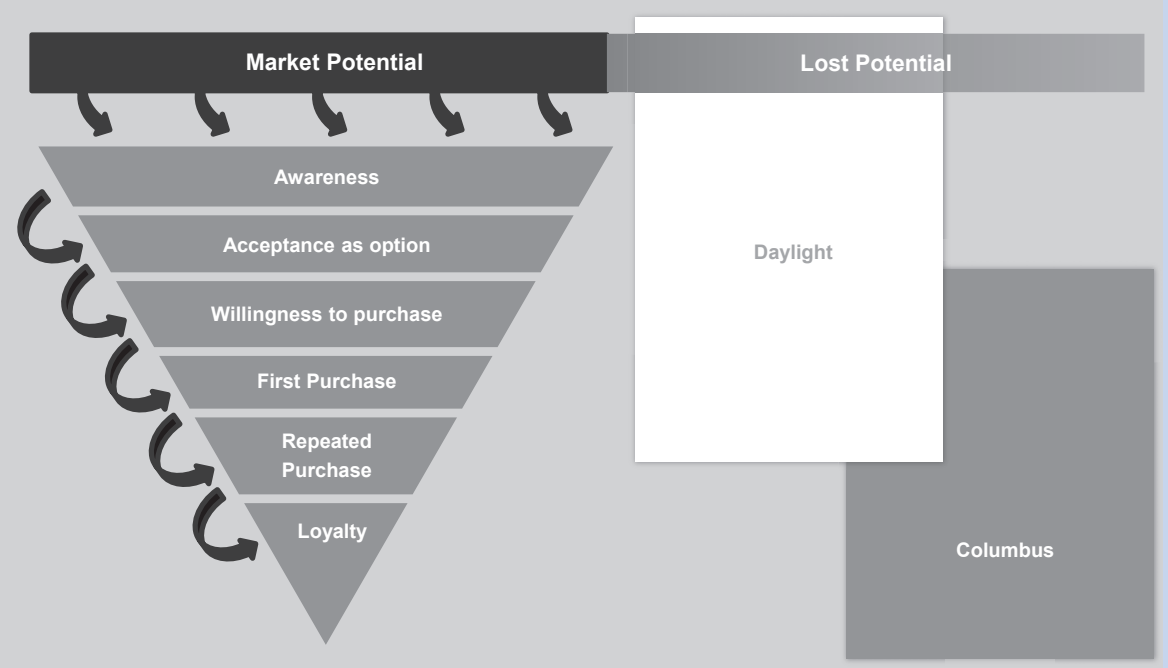




\section{"DAYLIGHT" - Without Awareness no interest and no order}

How should the company define to which countries a suggested strategy applies and to which countries it does not? At one point the company has identified the key question "Do potential customers already know Dräger's brand and products?" as an important baseline for all marketing and communication issues. And to answer this question to all extents it decided to conduct a market survey to fill some gaps in the market knowledge.

The so called "DAYLIGHT"-survey was conducted as a starting point to investigate the level of awareness of Dräger's brand and products, both unguided as well as guided. Purpose of the study is not to cover customer opinions but to learn more the mindset of the target groups in total and their brand and media propositions.

So far this awareness market research has been performed twice and the survey results gave the company interesting market insights and updated information on their target groups' mechanisms.

The survey results answer questions such as:

- which part of the target group knows Dräger already?

- and if they know them, what is their opinion about Dräger?

\section{Intentions and impact of the awareness survey}

The objective of the market research was to discover the knowledge and the attitudes of market potentials - both towards Dräger as towards Dräger's competitors - and to understand the usage and the relevance of information channels.

\section{So DAYLIGHT}

- determines the current level of awareness,

- provides directions where to focus with our awareness efforts,

- helps us to develop an effective program to increase awareness and

- provides a baseline for measuring marketing programs.

The insights had an important impact on the conception of communication activities and were used as a valuable input for the whole communication planning process in the following years. Increasing brand awareness was set as one of the main communication targets in several countries afterwards and several interesting projects have been consistently and quickly implemented.

\section{A short definition of brand awareness}

Brand awareness: extent to which a brand is recognized by potential customers, and is correctly associated with a particular product.

Expressed usually as a percentage of target market, brand awareness is the primary goal of advertising in the early months or years of a product's introduction. 


\section{"COLUMBUS" - A worldwide customer satisfaction and loyalty survey with the aim to measure and optimize customer care processes.}

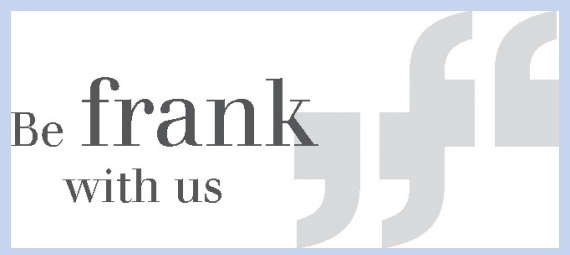

Gaining a neutral perspective on the market and finding out what customers think is an important marketing task. Only companies who know their customers' needs and wants are in position to improve. Regular communication and constructive criticism are the basis of relationship built on trust. Thus as second brand survey, Dräger conducts its external customer satisfaction research, the so-called "COLUMBUS" approach. This involves asking thousands of safety and medical markets customers by existing customer data bases all over the world questions on their experiences with Dräger:

- how satisfied are they with products, contact, advice, quality and all the various elements of customer orientation (Performance Areas described by a group of items which belong to the topic).

It has been already conducted for several times - in a long term approach.

With the help of the "COLUMBUS" survey Dräger discovers

- what the customers expect from the company, its products and services and

- whether the customer requirements with regard to e.g. the quality of customer support are met.

\section{KPIs and impact of the customer satisfaction research}

With the help of a questionnaire, a number of aspects in the relationship between a customer and the supplier are researched, pooled in a large and detailed data base.

As baseline for strategic decisions the information is summarized for the internal stakeholder and express key findings in a few characteristics. The results are reported in a Customer Loyalty Index (CLI), a Customer Satisfaction Index (CSI) and Performance Areas (PAs). These are abstract values which allow a compressed overview for management, especially as simply structured numerical insights for the direct benchmark with competitors. 
Key Performance Indices and other classifications for comparisons

A) Customer Loyalty Index (CLI)
The CLI is a compacted, abstract value that can neither be directly determined
nor influenced. It is the means of
- the likelihood of recommendation
- the likelihood of repurchase
regarding the respective main supplier.

\section{B) Customer Satisfaction Index (CSI)}

The Customer Satisfaction Index (CSI) is also an abstract value and cannot be influenced directly.

The CSI is composed by 50 percent asked overall satisfaction with the main supplier and by 50 percent results (satisfactions) regarding the so-called Performance Areas.

C) Performance Areas (PAs)

The Performance Areas also cannot be directly influenced as parameters. They form a sum value for the results of single items (questions) which belong together in regards to their topic (relationship aspects or procedure).

The performance areas have been examined by means of a multiple regression analysis to find out which input they provide for the Customer Loyalty Index (CLI). That means it was analyzed which coherences are existing between a Performance Area and the CLI. According to this analysis the Performance Areas are influencing the Customer Satisfaction Index (CSI).

Beside the strategic issues the goal of the survey is to foster improvement of issues that can be influenced by sales or other functions (marketing, logistics, quality etc.):

- Uncovering opportunities for sales and service improvement in the surveyed countries as well as a bilateral clarification up to the learning effect for the operational sales team / service team in the country

- Derivation of fields of functional action, sitting up on a continuous improvement process to improve things sustainable.

- Uncovering deficiencies that can be described in detail by customer segments, markets and industries, cultures, media and critically analyzing where paradigm shifts may be mandatory, that means major corrections to the corporate strategy.

After each loop fields of action and corresponding measures are identified together with individual countries and business sectors. 


\section{Summary}

Dräger wants to increase loyalty and thus support sales. This is only possible if the company obtains a complete picture of the market and customer and when weak points in all aspects such as communications or how easy it is to contact staff are addressed openly and honestly. Using the responses from the survey, they can determine then what they could have done differently in the past and what they can do better in future.

The findings from the studies affect marketing and business decisions steadily over years. "DAYLIGHT" and "COLUMBUS" are elements of a regulative, and self-criticism. They depicts what is happening, how it is happening and how it is seen and experienced in individual cases or within groups in relevant markets.

To raise the Management by KPI's to a next level, Dräger is implementing a continuous measurement process to recognize trends at an early stage. Since 2013 project-related surveys are in place. As part of that "BRIDGE" program the company asks their customers to rate their satisfaction with the performance after a business transaction, because they are best suited to assess the quality. All figures gave the management hints for future fields of action.

\section{Technology for Life since 1889}

\section{Excerpt from corporate history}

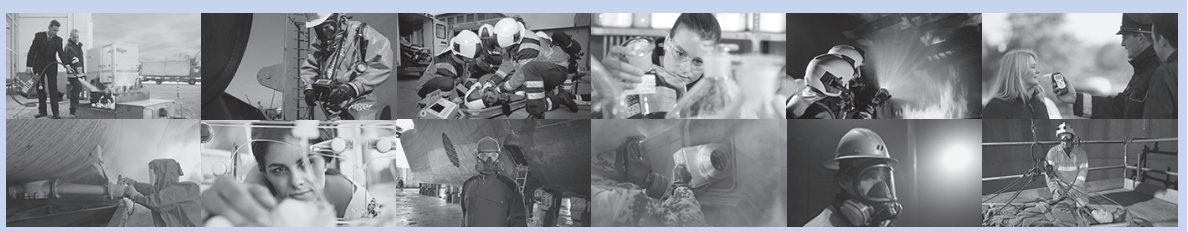

1889 Founding of the workshop and store "Dräger \& Gerling"; The first patent: Reducing valve for carbon dioxide - the Lubeca valve

1895 Basic research on oxygen proportioning

1902 Roth-Dräger mixed anesthetic apparatus

1904 Model 1904/09 breathing apparatus

1907 The first ventilator: Pulmotor

1924 First closed-circuit anesthetic apparatus for acetylene

1926 Model A anesthetic apparatus

1947 Iron lung ventilator for long-term use

1950 Model G multi-gas anesthetic apparatus

1951 The first incubator for newborns with air monitoring

1964 Incubator 6000/6500 for newborns

1968 Founding of North American Draeger Inc.

1975 PA 80 self-contained breathing apparatus becomes international standard 
1979 The company goes public with the issue of preferred shares

1980 Stationary detection devices

1989 Babylog 8000 intensive care ventilator for infants and premature babies

1993 Recognition as "most family-friendly large concern"

1995 First comprehensive patient data management system

2001 Savina mobile ventilator and Caleo incubator

2003 Stock exchange listing on the German TecDAX index

2004 Acquisition of the American incubator specialist Air-Shields

2005 Stefan Dräger becomes Chairman of the Executive Board

2008 Dräger DrugTest 5000 drug analysis system

2009 Zeus Infinity Empowered anesthesia workstation

2011 Making Ventilation Visible: PulmoVista 500 lung function monitor

2012 Foundation of the Dräger Academy; Perseus A500 user-configurable anesthesia workstation; Polytron 5000 stationary gas detection; Rescue trains for Deutsche Bahn

2013 HPS 7000 firefighter helmet

2014 Dräger celebrates 125 years

\section{Questions}

1. What are KPIs?

2. Please explain the long term consideration of KPIs.

3. Why is it so important for a B2B-company to have knowledge about the level of awareness in a target group?

4. Why is it so important for a B2B-company to measure the level of customer satisfaction and to make large investments in market research in this regard?

5. You had been provided with empirical results by the loyalty- and satisfaction survey mentioning the technical service in two regions. You can see the distance between the results of your company and those of the competitors both from the customers' view.

Which differences in the comparison of the regions seem to be particularly critical? Give reasons for your selection!

6. You had been provided with the results of the awareness survey featuring the information channels which are used by potential buyers in the Asia/Pacific region.

a. You would like to improve the communication base for your company in the Asian/Pacific countries. Which media or communication channels will you need to check to find out how appropriate your company performs or does not perform there today?

b. A marketing head who had been working several years in China had stressed more than one time that the information by public authorities are by far the most important information sources in Asia. How will you argue, when you will meet him the next time? 
7. You had been provided with the results of the awareness survey featuring the branding associations, information deficits, and the expectations regarding different manufacturers by the view of people who require products from the defined product group.

By which arguments the company might treat the potential weakness point "expensive"? 